\title{
Full Parameterisation Matters for the Best Performance of Crop Models: Inter-comparison of a Simple and a Detailed Maize Model
}

\author{
A. M. Manschadi ${ }^{1}$ - J. Eitzinger ${ }^{2} \cdot$ M. Breisch $^{1} \cdot$ W. Fuchs $^{1} \cdot$ T. Neubauer $^{3} \cdot$ A. Soltani $^{4}$
}

Received: 19 June 2020 / Revised: 14 September 2020 / Accepted: 25 September 2020 / Published online: 12 October 2020

(c) The Author(s) 2020

\begin{abstract}
Process-based crop growth models have become indispensable tools for investigating the effects of genetic, management, and environmental factors on crop productivity. One source of uncertainty in crop model predictions is model parameterization, i.e. estimating the values of model input parameters, which is carried out very differently by crop modellers. One simple (SSM-iCrop) and one detailed (APSIM) maize (Zea mays L.) model were partially or fully parameterized using observed data from a 2-year field experiment conducted in 2016 and 2017 at the UFT (Universitäts- und Forschungszentrum Tulln, BOKU) in Austria. Model initialisation was identical for both models based on field measurements. Partial parameterization (ParLevel_1) was first performed by estimating only those parameters related to crop phenology. Full parameterization (ParLevel_2) was then conducted by estimating parameters related to phenology plus those affecting dry mass production and partitioning, nitrogen uptake, and grain yield formation. With ParLevel_1, both models failed to provide accurate estimation of LAI, dry mass accumulation, nitrogen uptake and grain yield, but the performance of APSIM was generally better than SSM-iCrop. Full parameterization greatly improved the performance of both crop models, but it was more effective for the simple model, so that SSM-iCrop was equally well or even better compared to APSIM. It was concluded that full parameterization is indispensable for improving the accuracy of crop model predictions regardless whether they are simple or detailed. Simple models seem to be more vulnerable to incomplete parameterization, but they better respond to full parameterization. This needs confirmation by further research.
\end{abstract}

Keywords Crop model $\cdot$ Simulation $\cdot$ Parameterization $\cdot$ Uncertainty

\section{Introduction}

Dynamic process-based crop models simulate crop development and growth processes in response to climatic variables, soil conditions, management factors, and cultivar-specific genetic characteristics. The major processes simulated in crop models include crop phenological development and

A. M. Manschadi

manschadi@boku.ac.at

1 Department of Crop Sciences, Institute of Agronomy, BOKU University, Vienna, Austria

2 Department of Water-Atmosphere-Environment, Institute of Meteorology and Climatology, BOKU University, Vienna, Austria

3 Institute of Information Systems Engineering, Vienna University of Technology, Vienna, Austria

4 Agronomy Group, Gorgan University of Agricultural Sciences and Natural Resources, Gorgān, Iran dry mass growth, leaf area development, light interception and utilisation, crop demand for water and nutrients, yield formation, dynamics of soil water, carbon, and nitrogen $(\mathrm{N})$, evapotranspiration, and the effect of atmospheric carbon dioxide concentrations $\left(\mathrm{CO}_{2}\right)$ on photosynthesis and wateruse efficiency. Due to these capabilities, crop models have widely been used in applications as diverse as optimising the application of fertilizers for improved crop productivity and environmental benefits (Moeller et al. 2007, 2013; Manschadi et al. 2014; Tang et al. 2018), estimating crop water requirements and optimizing irrigation scheduling (e.g. Dalla Marta et al. 2018; Gobin et al. 2017), modelling the value of adaptive plant traits to support crop improvement (Manschadi et al. 2006; Chenu et al. 2018; Hammer et al. 2019), operational crop yield forecasting (Van der Velde and Nisini 2018), and assessing impacts of climate change and variability on crop growth and yield formation at regional, national, and global scales (White et al. 2011; Rötter et al. 2012; Thaler et al. 2012; Eitzinger et al. 2013a; Devkota 
et al. 2013; Asseng et al. 2013; Rosenzweig et al. 2014; Ebrahimi et al. 2016).

Crop models commonly require a large number of input data including daily weather parameters (such as temperature, precipitation and solar radiation), detailed soil properties and initial soil conditions, cultivar-specific genetic parameters, and information on crop management practices. The sources of uncertainty in crop model projections include (1) model input data (e.g. soil physical properties and initial water, carbon, and $\mathrm{N}$ conditions), (2) model parameterization (i.e. inadequate estimation of cultivar-specific phenological development and parameterization of crop growthrelated processes), (3) model structure (inadequate scientific representation of crop response to temperature, water and nutrient stress, $\left[\mathrm{CO}_{2}\right]$ levels and any other crop growth limiting factors or combination of those), (4) human errors in set-up and configuration of simulation runs, crop and soil parameterization, and interpretation and communication of simulation results (Palosuo et al. 2011; Rötter et al. 2011; Eitzinger et al. 2013b; Ewert et al. 2015).

A common approach in assessing uncertainty in crop models is the use of model inter-comparisons. That involves repeating the same simulation with a selection of crop models, which differ in their representation of processes determining crop responses to growing conditions, and evaluating their outputs for a range of scenarios (Palosuo et al. 2011; Rötter et al. 2011; Asseng et al. 2013; Bassu et al. 2014). Such crop model inter-comparisons are similar to ensembles of climate models, which have been used to address the uncertainty associated with projecting climate scenarios due to, for instance, uncertainties in predicting the trajectories of future greenhouse gas emissions (Knutti and Sedlácek 2013).

It is also widely recognised that an adequate level of parameterization, i.e. obtaining parameters governing crop phenology and growth processes, is indispensable to reduce the uncertainty and improve the accuracy of crop model simulations (Rötter et al. 2011; Wallach et al. 2011; Bassu et al. 2014; Salo et al. 2016). It is common to use calibration as a synonym for parameterization. Crop model parameters can be obtained via references, in-situ field measurements, and/ or a calibration procedure. Thus, calibration is one possible way of model parameterization in which the model is tested indirectly using different values for one or several parameters within the simulation process of higher end variables, which are more often available from measurements or observations, such as crop yield or leaf area. The parameterization of a process and its simulated result that match closest the observed variables is selected as the "calibrated" parameter estimate. Sinclair and Seligman (1996) criticized incorrect use of 'calibration' as being synonymous with parameterization. Calibration is better to be limited to those cases in which one or several parameters are estimated or adjusted by "calibrating" the whole model to achieve outputs that match relevant observations. In many cases, calibration is performed because the parameters under concern are not easily measurable or unavailable (Grassini et al. 2015).

The performance of crop models in simulating crop responses to climatic, soil, genetic, and management factors depends largely on the level of detail in the input information available for model parameterization. For instance, Bassu et al. (2014) demonstrated that a low-level model parameterization based on a set of minimal information (e.g. soil characteristics, management inputs, and crop phenology) can lead to high uncertainty in simulated responses of crop yield to climate change, whereas parameterising crop models to simulate more accurately the time series of above-ground dry mass, leaf area index, soil water and $\mathrm{N}$ contents, and plant $\mathrm{N}$ uptake, can significantly reduce variation among crop models and improve the accuracy of simulation results. In a recent inter-comparison of multiple global gridded crop models, Rosenzweig et al. (2014) showed that considering the effects of $\mathrm{N}$ stress on crop growth processes results in much severe projected impacts from climate change, with significant implications for designing adaptation options. This is because crop $\mathrm{N}$-acquisition and biological $\mathrm{N}$ fixation will be negatively affected by climate change-induced drought stress combined with higher temperatures (StClair and Lynch 2010; Devkota et al. 2013).

The objective of this study was to compare the effect of two parameterization levels on the performance of APSIM (Agricultural Production Systems sIMulator, Holzworth et al. 2014) and SSM-iCrop (Soltani and Sinclair 2012, 2015) models for simulating leaf area development, plant $\mathrm{N}$ uptake and partitioning, dry mass growth, and yield formation using detailed experimental data from two maize experiments conducted in a temperate central European climate.

\section{Materials and Methods}

\section{Field Experiments}

Plant and soil data were collected from two field experiments conducted in 2016 and 2017 at the UFT (Universitäts- und Forschungszentrum Tulln, BOKU), Lower Austria $\left(48^{\circ} 19^{\prime} \mathrm{N}, 16^{\circ} 04^{\prime} \mathrm{E}, 178 \mathrm{~m}\right.$ a.s.1.). Maize (Zea mays L., cv. P8400) was sown on 9 and 11 May in 2016 and 2017, respectively. The soil at the experimental site is classified as a chernozem with silty loam in the topsoil. The detailed water holding characteristics and organic matter content of the soil profile are presented in Tables 2 and 3 . The mean annual precipitation of the site is $625 \mathrm{~mm}$ and mean annual temperature is $9.7^{\circ} \mathrm{C}$ (reference period 1981-2010) with a distinct seasonal change 
of both temperature and precipitation at its maximum in the summer (continental climate type).

Experimental design was a randomized split-plot with four replications. The setup included five different $\mathrm{N}$ fertilization levels: 0 (N0), 40 (N1), $80(\mathrm{~N} 2), 120(\mathrm{~N} 3), 160$ (N4) $\mathrm{kg} / \mathrm{ha}$, applied in two rates at two-leaf and two-node phenological stages of maize. In each plot $(10 \times 6 \mathrm{~m}), 8$ rows of maize were planted with a row spacing of $0.75 \mathrm{~m}$ and a plant density of 7.5 plants $\mathrm{m}^{-2}$. Due to very high initial soil mineral nitrogen (Nmin) in 2016, the experiment in 2017 was set up on the exact same area and plot arrangement as in 2016 to make use of lower initial soil Nmin contents in the N0 plots. In 2017, the experiment was irrigated three times (21 June, 5 July, and 20 July) with a total of $65 \mathrm{~mm}$ water to avoid severe drought stress. Pests, diseases, and weeds were controlled with common on-station measures.

In both seasons, three randomly chosen plants per plot were marked for weekly scoring of phenology using the growth scale BBCH (Biologische Bundesanstalt, Bundessortenamt and CHemical industry; Meier 2001) and main-stem leaf number. Sequential destructive plant samples ( 8 plants per plot) were taken for measuring crop dry mass, leaf area development, $\mathrm{N}$ uptake, and grain yield. Plant samples were separated into senesced and photosynthetic active (green) leaf blades, stems (including leaf sheaths), ears, and grains. A subsample of green leaves was taken to measure leaf area (LI-3100C Area Meter, LI-COR, USA). All samples were dried at $60{ }^{\circ} \mathrm{C}$ for $72 \mathrm{~h}$ to determine tissue dry mass.

At each plant sampling date, gravimetric soil water content was also determined in $0-10,10-30,30-60$, 60-90, and 90-120 cm soil layers in all plots of two replications by drying samples at $105^{\circ} \mathrm{C}$ for $72 \mathrm{~h}$. The soil bulk density in the corresponding soil layers was determined by digging a pit and sampling horizontally into the pit wall using an open-ended, thin-walled sampling ring of $70 \mathrm{~mm}$ diameter and $50 \mathrm{~mm}$ length. The gravimetric soil water measurements were converted to volumetric water content using the bulk density values. The drained upper limit of the soil was measured using the ponded method (Dalgliesh and Foale 1998). The crop lower limit of soil water extraction was estimated by preventing the infiltration of rainfall into the soil during the grain-filling phase of maize. For this an area of $6 \mathrm{~m}^{2}$ in the border rows of the maize experiment in 2017 was covered with an opaque vinyl cover and gravimetric soil water was determined at crop harvest. In addition, soil samples taken at maize sowing, silking, and physiological maturity were sent to a commercial soil laboratory for measuring Nmin $\left(\mathrm{NO}^{-}\right.$and $\mathrm{NH}^{+}{ }^{+}$) and organic carbon.

\section{Statistical Analysis}

Analysis of variance (ANOVA) was carried out using the GLM (General Linear Model) procedure of SAS (Statistical Analysis System) package (SAS-Institute 2008). Significant differences in the mean values were determined by Tukey's HSD (honest significant difference) test at a significance level of 0.05. Graphs were produced using SigmaPlot (Version 14.0, Systat Software Inc., San Jose, USA).

\section{Description of Crop Models}

APSIM is a detailed crop model compared to the simple model SSM-iCrop. The Agricultural Production Systems sIMulator (APSIM) is internationally recognised as one of the most advanced and comprehensive crop/cropping system models for simulating the effects of genetic factors, environmental variables, and management decisions on production (crops, pasture, trees, livestock), profits, and environmental processes (e.g. soil erosion, nitrate leaching) (https://www. apsim.info, Holzworth et al. 2014). APSIM incorporates a generic crop model, which utilizes a library of routines for simulating growth and development processes for more than 20 crop species including maize (Soufizadeh et al. 2018). APSIM has been used in a broad range of applications including supporting on-farm decision making, designing farming systems for production or resource-management objectives, guiding crop breeding strategies, assessing risk for government policy-making, and evaluating management options for adaptation to climate change and variability (Manschadi et al. 2006; Moeller et al. 2007, 2013; Hochman et al. 2009; Huth et al. 2010; Lobell et al. 2015; Hammer et al. 2010, 2019; Wu et al. 2019).

Simple simulation models (SSM) are a group of crop models based on Sinclair's approach (Sinclair 1986; Soltani and Sinclair 2012; Sinclair et al. 2020) in crop modelling. The development and application of the models dates back to 1986 when a soybean model was developed (Sinclair 1986). The modelling framework was then improved and applied over the past 35 years to nearly all major grain crops including maize (Sinclair and Muchow 1995). A complete description of SSM principles and procedures can be found in Soltani and Sinclair (2012). The model includes the key physiological processes to simulate crop responses to radiation-, water-, and nitrogen-limited conditions. SSMiCrop (Soltani et al. 2013; thereafter referred to as iCrop) is a research version of SSM that was first developed for wheat. iCrop uses identical sub-models to simulate crop processes in all grain crops except for phenology that can have its own specific sub-model depending on crop species under consideration. It uses a layered soil, simulates $\mathrm{N}$ fixation in grain legumes, and includes several physiological 
concepts to evaluate genetic improvement, such as limited transpiration rate (Messina et al. 2015) and drought survival (Ghanem et al. 2015). Sinclair et al. (2020) newly reviewed the application of SSM models in different crops.

A brief description of major crop processes in maize simulated by both models is provided here. Crop phenological development in both models is predicted as a function of temperature, photoperiod and water deficit. iCrop phenology sub-model is based on Kiniry (1991). APSIM simulates delay in phenology due to $\mathrm{N}$ stress but iCrop assumes no effect on phenology of $\mathrm{N}$ stress.

APSIM uses a detailed method to simulate leaf area development from prediction of leaf number and the size of individual leaves and adjusting it for water and $\mathrm{N}$ stresses. iCrop, however, simulates leaf area development using a simple approach based on the relationship between plant leaf area and main stem leaf (node) number and then adjusts it for water and $\mathrm{N}$ stresses. Phyllochron is fixed in iCrop but depends on the development stage in APSIM. New leaf expansion in APSIM is governed by bounding values of specific leaf area, so that leaves cannot be grown to be extremely 'thin' or 'thick'. This is not simulated in iCrop.

Dry mass production in iCrop is based on radiation use efficiency (RUE) concept in which RUE is adjusted for current day conditions of temperature and water deficit. The RUE concept is also used in APSIM, but it is limited to compute dry mass production under non-limited water conditions. Under water-limited conditions, dry mass production is obtained from available water for crop transpiration and transpiration efficiency; hence water uptake by the roots from the soil is needed to be simulated. RUE in APSIM is also $\mathrm{N}$ dependent but it is not in iCrop.

Simulation of dry mass partitioning is much simpler in iCrop and is a function of allometric relation between leaves and stem dry mass before silking. Between silking and beginning seed growth a fixed, negligible fraction of produced dry mass goes to leaves and the remaining is allocated to stem. Following the start of grain filling, all produced dry mass is allocated to the developing seeds and any possible leftover is partitioned to the stem. Ears without grains are not simulated by iCrop. APSIM uses dry mass partitioning coefficients to leaves, stem, and cobs that are depended on the development stage of the crop. Between emergence and flag leaf appearance, the fraction of dry mass that is provisionally allocated to the leaves decreases as the number of fully expanded leaves increases. Between tassel initiation and flag leaf appearance, the dry mass remaining after allocation to leaves is partitioned between stem and developing ears in a fixed ratio. After flag leaf appearance, dry mass is partitioned between stem and ears only, until partitioning to the grain starts at the onset of grain filling. While iCrop does not simulate root dry mass, APSIM accounts for root dry mass as a fraction of top dry mass and the fraction is specified for each growth stage.

Yield formation in iCrop is simulated based on linear increase in harvest index, but actual daily grain growth rate is limited to current crop dry mass production plus daily rate of translocated dry mass from vegetative organs. The translocation occurs only if daily dry mass production is not enough to support seed growth rate calculated from the slope of the linear increase in harvest index. Yield formation in APSIM is more detailed and relies on the simulation of grain number and grain size. Grain number is related to crop growth between tassel initiation and beginning seed growth using a genetic coefficient. Grain size is depended on grain growth rate, the effective grain-filling period, and dry mass re-translocation. If grain mass demand for a day exceeds the daily increase in dry mass, the shortfall will first be met through translocation from the stem and, if that is insufficient to meet the demand of the grain, through translocation from leaves.

The basics of plant $\mathrm{N}$ balance simulation in both models is more or less the same: before seed growth, daily demand for $\mathrm{N}$ is computed from new growth in LAI and stem and their critical $\mathrm{N}$ concentration. The demand is then adjusted for maximum rate of $\mathrm{N}$ uptake and the amount of soil $\mathrm{N}$ available for crop uptake. When $\mathrm{N}$ uptake rate does not fully meet the demand, the following responses occur sequentially. First, the concentration of N (N\%) in stem is decreased until stem N\% reaches its minimum. Second, when stem $\mathrm{N} \%$ reaches its minimum, leaf area development is inhibited and stem growth at minimum $\mathrm{N} \%$ is continued, as structural stem mass is required to support leaf growth. Third, leaves are senesced to provide $\mathrm{N}$ for stem growth with minimum $\mathrm{N} \%$. Thus, leaf senescence may occur during vegetative growth. After seed growth, daily $\mathrm{N}$ demand is obtained from seed growth rate multiplied by seed critical $\mathrm{N} \%$, but it is limited to daily extractable $\mathrm{N}$ from vegetative tissue plus soil $\mathrm{N}$ uptake. If $\mathrm{N}$ uptake from the soil is not sufficient to support seed growth, $\mathrm{N}$ is translocated from the leaves and stems to the seeds. $\mathrm{N}$ translocation from leaves results in leaf senescence. iCrop treats this concept simpler and needs less parameters compared to APSIM. iCrop relies on specific leaf $\mathrm{N}$ (SLN) in green and senesced leaves and N\% in green and senesced stems, but APSIM works with minimum, critical and maximum SLN and stem N\%. Minimum, critical and maximum stem N\% in APSIM are varied depending on development stage. While APSIM permits $\mathrm{N}$ dilution in leaves, this is not simulated in iCrop and any shortage in leaf $\mathrm{N}$ results in leaf senescence. In APSIM, $\mathrm{N}$ translocation to the grains is initially taken from the stem (plus cobs), and if this becomes insufficient then $\mathrm{N}$ translocation from the leaf occurs. In iCrop, $\mathrm{N}$ translocation from leaf and stem is proportional to their relative translocatable $\mathrm{N}$. 
Both models simulate soil water dynamic in multiple layers using a one-dimensional approach (cascade method). Water addition from rainfall or irrigation and water removal due to run-off, evaporation, transpiration (uptake) and drainage are accounted for. But the procedures are more detailed in APSIM, as it predicts water uptake by the roots. Both models simulate daily increase in effective rooting depth from a potential daily rate of increase that is adjusted for plant and soil conditions. iCrop computes water uptake as a function of calculated daily transpiration, but APSIM calculate water uptake based on soil water content via an exponential function, parameterized via an extraction decay constant $(k l)$ that incorporates the effects of both soil hydraulic conductivity and root length density on water uptake. The value of $k l$ must be determined for each soil layer. APSIM simulates upward movement of water, which is not simulated by iCrop. In iCrop, three water deficit factors are calculated from the fraction of available (transpirable) soil water in the crop root zone that are utilized to adjust dry mass production, leaf area expansion, and phenological development for water shortage. APSIM uses the ratio of actual growth from limited water to potential growth without water limitation to correct crop responses to water deficit.

Similarly, soil N balance in each layer is calculated by both models in which $\mathrm{N}$ addition due to mineralization and $\mathrm{N}$ fertilizer application and $\mathrm{N}$ removal due to volatilization, leaching and crop uptake are taken into account. Again, the methods used by APSIM are more detailed. For example, iCrop does not simulate soil temperature and air temperature is used instead. Soil $\mathrm{N}$ mineralization of organic $\mathrm{N}$ to ammonium $\left(\mathrm{NH}^{+}\right)$and the subsequent transformation to nitrate $\left(\mathrm{NO}^{-}\right)$is modelled as one transformation in iCrop, while these are treated as separate responses in APSIM. Soil organic $\mathrm{N}$ is considered as a single pool in iCrop but APSIM deals with several pools including fresh and permanent pools.

\section{Initialization and Parameterization of Crop Models}

To eliminate as much as possible, the differences between the two models in simulated soil water and $\mathrm{N}$ supply, as they interact strongly with crop canopy development and $\mathrm{N}$ uptake, the management and soil input information were set to those exactly done or measured in the field experiments in both models (see details in the "Results" section).

In terms of parameterization, first only the parameters related to crop phenology and leaf appearance on the mainstem were parameterized to ensure very similar simulations of crop phenological development and main-stem leaf number production from both models. This is referred to as partial parameterization (ParLevel_1). In the next step, the observed experimental data were used to derive the genetic parameters for dry mass production and partitioning, $\mathrm{N}$ uptake, and grain yield formation. This is referred to as full parameterization (ParLevel_2). It should be noted that in APSIM, crop parameters are divided into two parts; the larger fraction consists of parameters that are normally constant for all cultivars and the smaller fraction (i.e. cultivar-specific) includes those that can be modified for new cultivars. The cultivar-specific parameters of APSIM are mainly phenological parameters and parameters related to yield formation (potential grain size). In iCrop, however, there is not such a distinction and all genetic model parameters can be modified.

\section{Results}

\section{Field Experiments}

The cumulative rainfall during the maize growing season (May-September) in 2016 (379.3 mm) and 2017 (360.9 mm) was slightly lower than the long-term average in the same period (393 mm). Compared to 2016, the temporal pattern of precipitation in the drier season 2017 was less favourable for crop growth. The total precipitation received in May and June of 2017 was 38\% lower than that in 2016 (193.5 mm) (Fig. 1). Therefore, $65 \mathrm{~mm}$ irrigation water was applied in 2017 to avoid severe drought stress. The average monthly temperature was similar in both growing seasons, except for June and August 2017, which were warmer than those in 2016 (Fig. 1).

Due to more favourable growing conditions, the average maize total above-ground dry mass across all $\mathrm{N}$

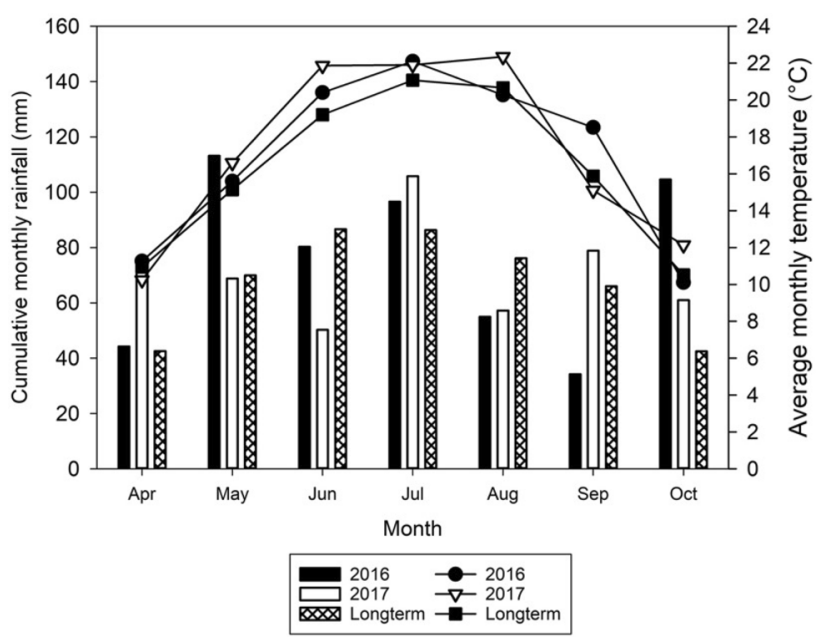

Fig. 1 Cumulative monthly rainfall (bars) and average monthly temperature (points) in maize growing seasons 2016 and 2017 at Tulln, Austria, compared to long-term historical data (1991-2017) 
treatments in 2016 was significantly higher than that in 2017 (Table 1). The difference in average grain yield in $2016\left(1154 \mathrm{~g} / \mathrm{m}^{2}\right)$ and $2017\left(1008 \mathrm{~g} / \mathrm{m}^{2}\right)$ was also statistically significant. Similarly, the total $\mathrm{N}$ uptake, grain $\mathrm{N}$ content, thousand seed weight, LAI at silking, and maximum main-stem leaf number were all higher in 2016 (Table 1). In both seasons, maize yield in unfertilised (N0) plots was significantly reduced but increasing the $\mathrm{N}$ fertiliser rate from 40 to $160 \mathrm{~kg} / \mathrm{ha}$ did not result in significant yield improvement (Table 1). Similarly, the yield components (grain number and thousand seed weight) and total above-ground dry mass were significantly reduced in unfertilised (N0) plots.

The total above-ground $\mathrm{N}$ uptake in 2016 followed the pattern observed for grain yield and dry mass. In 2017, however, maize plants responded to increasing $\mathrm{N}$ supply by accumulating more $\mathrm{N}$, reaching a maximum of $26.6 \mathrm{~g} /$ $\mathrm{m}^{2}$ in N4 plots (Table 1). On average, $73 \%$ of the total accumulated $\mathrm{N}$ was partitioned to grains, with no effect of $\mathrm{N}$ fertilization. Nitrogen stress resulted in a significant reduction in LAI of crops in unfertilised plots in both seasons, but crop phenology and main-stem leaf number were not affected by $\mathrm{N}$ treatment. Other physiological traits, such as specific leaf nitrogen (SLN, $\left.\mathrm{g} / \mathrm{m}^{2}\right)$ and tissue $\mathrm{N}$ concentration, showed significant responses to $\mathrm{N}$ supply (data will be presented in the sections comparing observed with simulated results).

\section{Initialization of Crop Models}

Careful initialisation was necessary to ensure that simulation results are varied only due to parameterization. Thus, the soil input data in both models were first set to the same values, which were derived from the ponding experiment and measurements conducted during the two growing seasons (Table 2). Second, the simulated potential evapotranspiration and soil evaporation by both models were compared to ensure similar levels of water losses from the soil (Fig. 2). Third, the initial parameters for simulating the soil $\mathrm{N}$ dynamic were adjusted in both models. For the initial soil mineral $\mathrm{N}$ content, the measured Nmin data per layer were used. The data on measured soil organic $\mathrm{C}$ were used to estimate soil organic $\mathrm{N}$ in each layer assuming a C:N ratio of 10:1 (BMLFUW 2017). The parameters FBiom (fraction of the more labile, soil microbial biomass and microbial products) and FInert (the rest of the soil organic matter) for APSIM and FMIN (fraction of soil organic $\mathrm{N}$ available for mineralisation) for iCrop were determined based on a simple $\mathrm{N}$ balance calculation for the N0 treatment in 2017. These data allowed the assessment of potential soil $\mathrm{N}$ supply to an unfertilised maize crop. The soil $\mathrm{N}$ input parameters used in APSIM and iCrop models are summarised in Table 3.

Using the initial parameter values for soil organic $\mathrm{C}$ and $\mathrm{N}$, the cumulative $\mathrm{N}$ mineralisation in $\mathrm{N} 0$ treatment was very similar in both models (Fig. 3). In highly fertilised plots of
Table 1 Mean and standard error (in parenthesis) of above-ground dry mass (DM), grain yield (GY), total $\mathrm{N}$ uptake (Nup), grain $\mathrm{N}$ content $(\mathrm{GN})$, thousand seed weight (TSW), grain number (GNo), leaf area index at silking (LAIsilk), and main-stem leaf number (MSLN) of maize grown in 2016 and 2017 at five $\mathrm{N}$ fertilisation levels

\begin{tabular}{|c|c|c|c|c|c|c|c|c|}
\hline Year and $\mathrm{N}^{\mathrm{a}}$ & $\mathrm{DM}\left(\mathrm{g} / \mathrm{m}^{2}\right)$ & $\mathrm{GY}\left(\mathrm{g} / \mathrm{m}^{2}\right)$ & $\operatorname{Nup}\left(g / m^{2}\right)$ & $\mathrm{GN}\left(\mathrm{g} / \mathrm{m}^{2}\right)$ & TSW (g) & GNo $\left(/ \mathrm{m}^{2}\right)$ & LAIsilk & MSLN \\
\hline \multicolumn{9}{|l|}{2016} \\
\hline N0 & $1967.2(74.9)$ & $1025.3(14.1)$ & $18.2(1.4)$ & $13.5(0.9)$ & $271.75(1.55)$ & $3773.2(54.5)$ & $3.69(0.06)$ & $18.59(0.08)$ \\
\hline N1 & $2241.8(72.2)$ & $1198.4(34.8)$ & $25.0(0.6)$ & $18.5(0.5)$ & $293.50(4.82)$ & $4085.0(120.5)$ & $4.02(0.07)$ & $18.42(0.37)$ \\
\hline $\mathrm{N} 2$ & $2242.5(51.5)$ & $1196.0(17.2)$ & $25.7(1.3)$ & $17.9(0.2)$ & $299.88(0.94)$ & $3988.7(64.1)$ & $3.93(0.10)$ & $18.50(0.17)$ \\
\hline N3 & $2242.1(51.4)$ & $1187.7(24.0)$ & $26.1(0.9)$ & $18.7(0.5)$ & $296.63(6.71)$ & $4007.9(93.1)$ & $4.20(0.10)$ & $18.38(0.21)$ \\
\hline N4 & $2241.1(32.8)$ & $1161.1(32.4)$ & $26.40 .2)$ & $18.2(0.3)$ & $294.63(4.33)$ & $3939.3(70.8)$ & $4.12(0.04)$ & $18.58(0.25)$ \\
\hline \multicolumn{9}{|l|}{2017} \\
\hline No & $1478.8(49.1)$ & 768.0 (24.4) & $12.1(0.7)$ & $8.8(0.6)$ & $226.45(7.05)$ & 3398.1 (128.1) & $3.03(0.14)$ & $17.92(0.16)$ \\
\hline N1 & $1855.4(72.1)$ & $1012.7(23.8)$ & 19.8 (1.6) & $15.0(1.4)$ & $257.68(6.98)$ & 3936.8 (123.5) & $3.46(0.15)$ & $17.75(0.08)$ \\
\hline $\mathrm{N} 2$ & 1934.3 (69.5) & $1061.0(34.6)$ & $21.2(1.3)$ & $16.1(0.9)$ & $268.48(3.43)$ & 3951.4 (112.6) & $3.47(0.03)$ & $17.50(0.32)$ \\
\hline N3 & $2019.1(41.2)$ & 1091.7 (17.9) & $25.5(0.9)$ & $19.5(0.5)$ & $273.29(3.17)$ & 3998.5 (110.2) & $3.48(0.08)$ & $17.84(0.10)$ \\
\hline N4 & $2042.5(54.2)$ & $1106.1(27.5)$ & $26.6(1.6)$ & $19.6(1.1)$ & 282.15 (4.33) & $3919.9(72.6)$ & $3.67(0.07)$ & $17.75(0.25)$ \\
\hline Year & $* * *$ & $* * *$ & $* * *$ & $* *$ & $* * *$ & ns & $* * *$ & $* * *$ \\
\hline $\mathrm{N}$ & $* * *$ & $* * *$ & $* * *$ & $* * *$ & $* * *$ & $* * *$ & $* * *$ & ns \\
\hline Year $\times N$ & $\mathrm{~ns}$ & $\mathrm{~ns}$ & $*$ & $* *$ & ** & ns & ns & ns \\
\hline
\end{tabular}

$n s$ not significant

***Significant at $\mathrm{p}<0.001, * *$ significant at $\mathrm{p}<0.01$, *significant at $\mathrm{p}<0.05$

${ }^{\mathrm{a}} \mathrm{N} 0, \mathrm{~N} 1, \mathrm{~N} 2 \mathrm{~N} 3$, and N4 denote fertiliser rates of $0,40,80,120$, and $160 \mathrm{~kg} / \mathrm{ha}$ 
Table 2 Soil water input parameters used for the initialisation of iCrop and APSIM models for 2016 and 2017 growing seasons

\begin{tabular}{|c|c|c|c|c|c|c|c|c|c|}
\hline \multirow[t]{2}{*}{ Layer } & \multirow[t]{2}{*}{ Depth $(\mathrm{cm})$} & \multirow[t]{2}{*}{ SAT $\left(\mathrm{m}^{3} / \mathrm{m}^{3}\right)$} & \multirow[t]{2}{*}{$\operatorname{DUL}\left(\mathrm{m}^{3} / \mathrm{m}^{3}\right)$} & \multirow[t]{2}{*}{$\operatorname{LL}\left(\mathrm{m}^{3} / \mathrm{m}^{3}\right)$} & \multirow[t]{2}{*}{$\operatorname{ADRY}\left(\mathrm{m}^{3} / \mathrm{m}^{3}\right)$} & \multicolumn{2}{|l|}{ iniWL } & \multirow[t]{2}{*}{ DRAINF } & \multirow[t]{2}{*}{$\mathrm{BDL}\left(\mathrm{g} / \mathrm{cm}^{3}\right)$} \\
\hline & & & & & & 2016 & 2017 & & \\
\hline 1 & $0-10$ & 0.442 & 0.392 & 0.160 & 0.110 & 0.277 & 0.181 & 0.800 & 1.372 \\
\hline 2 & $10-30$ & 0.425 & 0.375 & 0.150 & 0.120 & 0.300 & 0.311 & 0.400 & 1.497 \\
\hline 3 & $30-60$ & 0.431 & 0.407 & 0.200 & 0.200 & 0.310 & 0.283 & 0.300 & 1.490 \\
\hline 4 & $60-90$ & 0.434 & 0.384 & 0.150 & 0.150 & 0.280 & 0.238 & 0.300 & 1.421 \\
\hline 5 & $90-120$ & 0.347 & 0.297 & 0.130 & 0.130 & 0.227 & 0.205 & 0.300 & 1.479 \\
\hline
\end{tabular}

$S A T$ saturated soil water content, $L L$ and $D U L$ upper and lower limit of plant-available soil water, $A D R Y$ air-dry soil water content, iniWL initial soil water, DRAINF drainage factor, $B D L$ bulk density
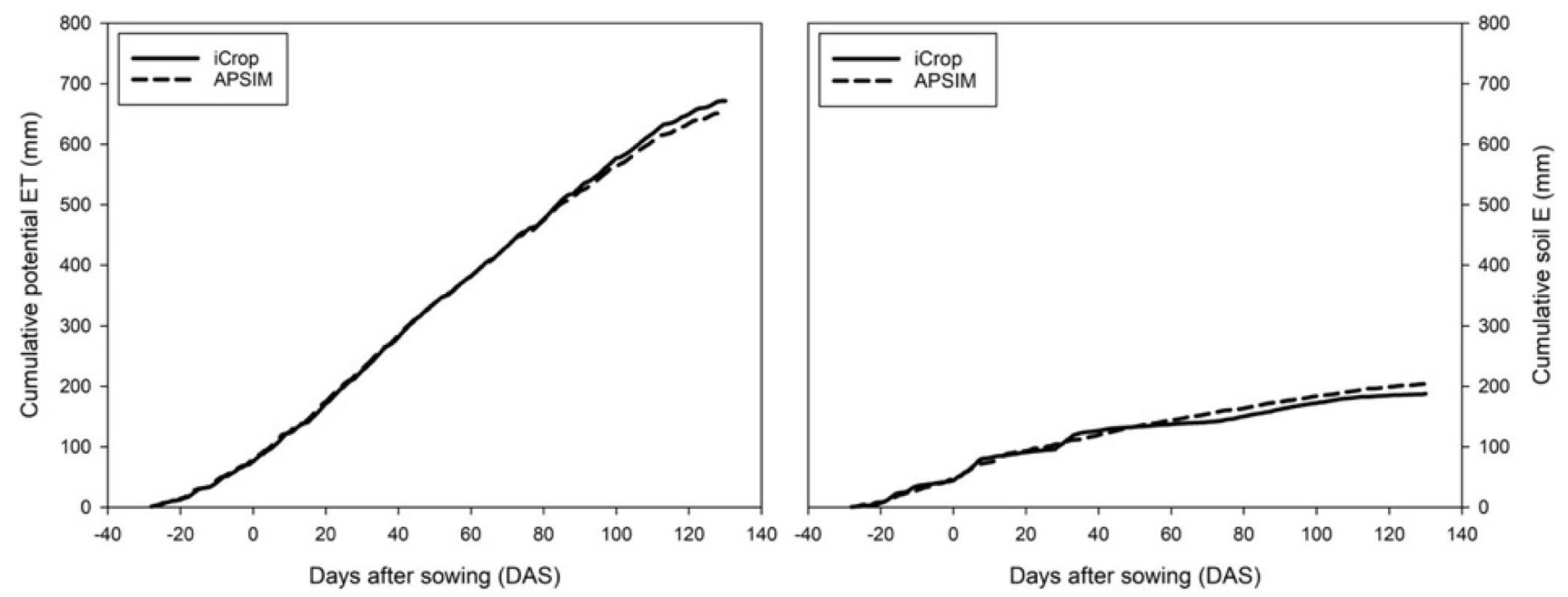

Fig. 2 Cumulative potential evapotranspiration (ET) and soil evaporation (E) simulated by iCrop and APSIM models for N0 (unfertilised) and N4 (160 kg/ha) nitrogen treatments in 2017 maize experiment

Table 3 Soil nitrogen input parameters used for the initialisation of iCrop and APSIM models for 2016 and 2017 growing seasons

\begin{tabular}{|c|c|c|c|c|c|c|c|c|c|c|c|c|}
\hline \multirow[t]{4}{*}{ Layer } & \multirow[t]{4}{*}{ Depth $(\mathrm{cm})$} & \multicolumn{2}{|l|}{ iCrop } & \multicolumn{3}{|c|}{ APSIM } & \multirow{2}{*}{\multicolumn{6}{|c|}{$\frac{\text { iCrop and APSIM }}{\text { Nmin (kg/ha) }}$}} \\
\hline & & \multirow[t]{3}{*}{ NORG\% } & \multirow[t]{3}{*}{ FMIN } & \multirow[t]{3}{*}{ OC\% } & \multirow[t]{3}{*}{ FBiom } & \multirow[t]{3}{*}{ FInert } & & & & & & \\
\hline & & & & & & & \multirow[t]{2}{*}{2016} & \multicolumn{5}{|l|}{2017} \\
\hline & & & & & & & & NO & N1 & N2 & N3 & N4 \\
\hline 1 & $0-10$ & 0.181 & 0.045 & 1.805 & 0.025 & 0.400 & 12.61 & 12.30 & 15.13 & 16.15 & 14.62 & 17.32 \\
\hline 2 & $10-30$ & 0.181 & 0.045 & 1.805 & 0.025 & 0.600 & 25.22 & 24.59 & 30.27 & 32.30 & 29.25 & 34.63 \\
\hline 3 & $30-60$ & 0.148 & 0.010 & 1.478 & 0.010 & 0.800 & 50.37 & 15.65 & 20.79 & 22.80 & 25.03 & 31.07 \\
\hline 4 & $60-90$ & 0.102 & 0.005 & 1.020 & 0.005 & 0.900 & 34.11 & 7.04 & 11.51 & 17.06 & 14.92 & 29.42 \\
\hline \multirow[t]{2}{*}{5} & $90-120$ & 0.047 & 0.001 & 0.469 & 0.001 & 0.950 & 29.11 & 6.43 & 13.53 & 22.84 & 15.08 & 26.39 \\
\hline & & & & & & Sum & 151.4 & 66.0 & 91.2 & 111.1 & 98.9 & 138.8 \\
\hline
\end{tabular}

$N O R G$ organic nitrogen, FMIN fraction of soil organic N available for mineralisation, $O C$ soil organic carbon, FInert fraction of organic carbon that is not susceptible to decomposition, FBiom fraction of susceptible organic carbon, Nmin soil mineral $\mathrm{N}$ 

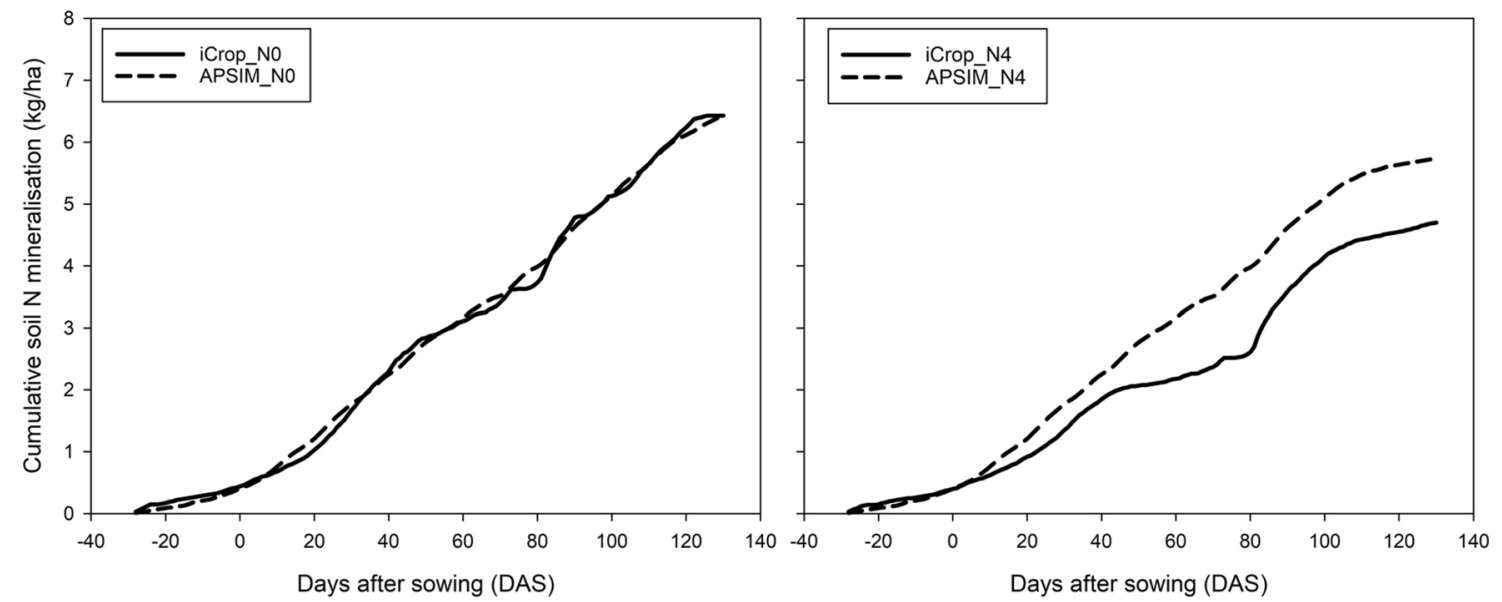

Fig. 3 Cumulative soil nitrogen $(\mathrm{N})$ mineralisation simulated by iCrop and APSIM models for N0 (unfertilised) and N4 (160 kg/ha) nitrogen treatments in 2017 maize experiment

$\mathrm{N} 4$, iCrop's prediction of $\mathrm{N}$ mineralisation was lower than in APSIM because mineralisation in iCrop is inhibited at high concentrations of $\mathrm{N}$ in the soil solution.

\section{Partial Parameterization (ParLevel_1)}

For the partial parameterization, first the model input parameters related to simulation of crop phenology were adjusted based on the observed data for cv. P8500 (Table 4). Both models simulated the dates of emergence, silking, and physiological maturity of maize plants within 2-3 days of observed dates in 2016 and 2017 seasons (data not shown). Second, the default values for leaf appearance rate on the main-stem (phyllochron) were modified in both models based on field data in order to minimise its effect on the simulation of leaf canopy development. Adjusting the phyllochron resulted in good prediction of leaf appearance on the main-stem in both growing seasons by both models (Fig. 4).

With the ParLevel_1, the simulation results for total above-ground dry mass, LAI, and plant $\mathrm{N}$ uptake from both models were not satisfactory. For unfertilised crops, iCrop simulated the temporal pattern of dry mass accumulation and $\mathrm{N}$ uptake very well but underestimated the growth and $\mathrm{N}$ accumulation of fertilised plants substantially (Fig. 5). APSIM, on the other hand, provided good simulation of dry mass and LAI under fertilised conditions, while underestimated $\mathrm{N}$ uptake in both fertilised and unfertilised plants. Although the observed data indicated a significant effect of $\mathrm{N}$ supply on LAI at silking (Table 1), neither models were capable of accounting for this accurately (Fig. 5). iCrop, in particular, was not able to simulate the interaction between $\mathrm{N}$ supply and leaf area

Table 4 Cultivar-specific input parameters for maize cv. P8500 used for the parameterisation of iCrop and APSIM for partial parameterisation (ParLevel_1)

\begin{tabular}{|c|c|c|}
\hline \multirow[t]{2}{*}{ Parameter } & \multicolumn{2}{|l|}{ Value } \\
\hline & Default ${ }^{\mathrm{a}}$ & Modified \\
\hline \multicolumn{3}{|l|}{ iCrop } \\
\hline Phyllochron $\left({ }^{\circ} \mathrm{Cd}\right.$ leaf-1) & 50 & 38.9 \\
\hline Biological days from sowing to emergence (bdSOWEMR, bd) & & 3.0 \\
\hline Biological day from emergence to end of juvenile (bdEMREJU, bd) & & 7.0 \\
\hline Biological day from silking/end of leaf growth on main-stem to physiological maturity (bdSILPM, bd) & & 32.5 \\
\hline \multicolumn{3}{|l|}{ APSIM } \\
\hline Phyllochron as a function of leaf number (leaf_app_rate, ${ }^{\circ} \mathrm{Cd}$ ) & 65 at 136 at 8 & 36 at 136 at 8 \\
\hline Thermal time from emergence to end of juvenile (tt_emerg_to_endjuv, ${ }^{\circ} \mathrm{Cd}$ ) & & 310 \\
\hline Thermal time from silking/flowering to start grain filling (tt_flower_to_start_grain, ${ }^{\circ} \mathrm{Cd}$ ) & & 170 \\
\hline Thermal time from silking/flowering to physiological maturity (tt_flower_to_maturity, ${ }^{\circ} \mathrm{Cd}$ ) & & 920 \\
\hline
\end{tabular}

${ }^{\mathrm{a}}$ For iCrop the default values were those reported in Soltani and Sinclair (2012) 


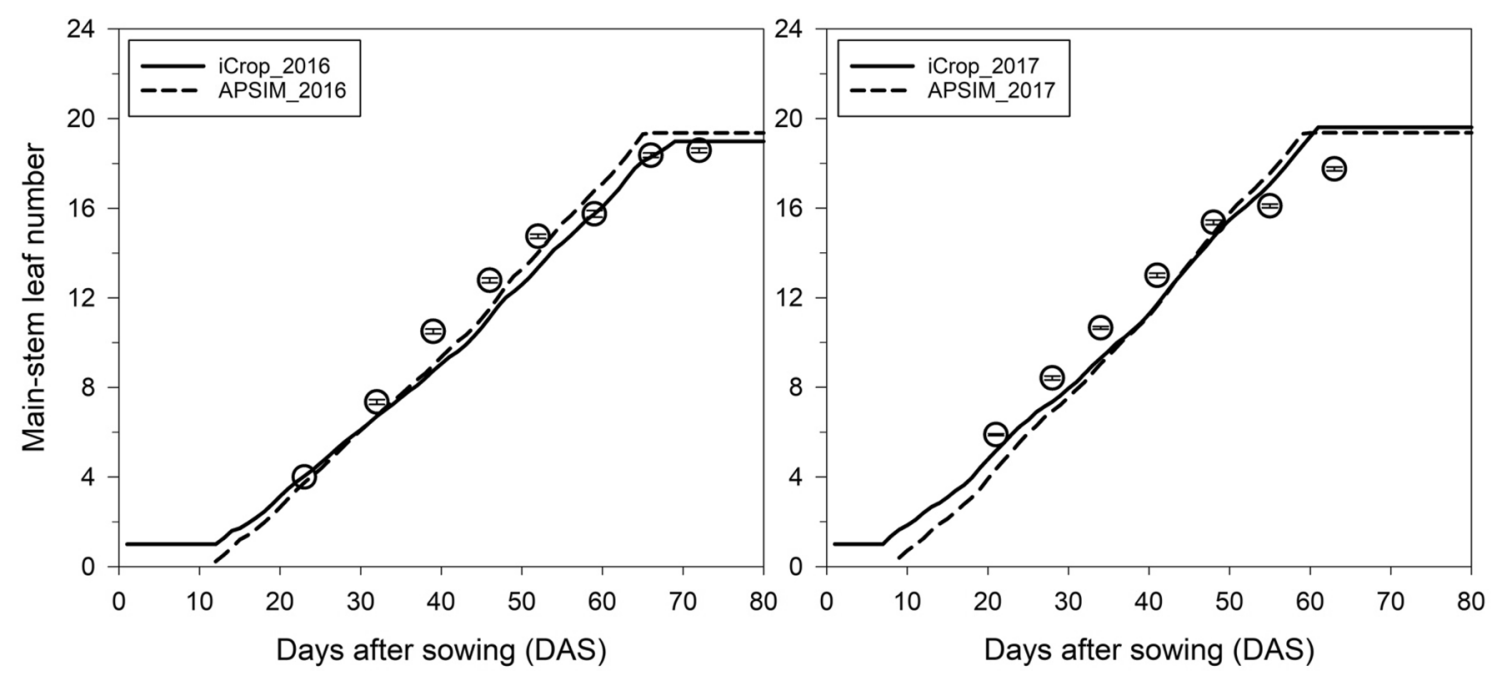

Fig. 4 Main-stem leaf number measured and simulated by iCrop and APSIM models for maize grown in 2016 and 2017 seasons; bars indicate standard error of measured values

development. With ParLevel_1, iCrop underestimated the total plant $\mathrm{N}$ uptake and grain yield of fertilised crops considerably (Fig. 6). APSIM also underestimated $\mathrm{N}$ uptake across all $\mathrm{N}$ treatments, but the simulated yields matched the observed data well (Fig. 6).

\section{Full Parameterization (ParLevel_2)}

In the next step of parameterization, the input parameters related to leaf canopy development, dry mass partitioning, plant $\mathrm{N}$ uptake, and grain filling were modified based on experimental data (for the values of parameters see Table 5).

Simulation of LAI in iCrop depends on the coefficient PLAPOW, which describes the power relationship between plant leaf area and main-stem leaf (node) number. This parameter was derived from experimental data (Fig. 7). Furthermore, the parameters describing the biphasic pattern of dry matter partitioning to the leaves during the vegetative growth in iCrop were calculated by plotting leaf dry matter against total dry matter (Fig. 8). The leaf partitioning coefficients at lower (FLF1A) and higher (FLF1B) levels of total crop mass and the inflection point between the stages (WTOPL) were $0.6,0.16$, and $239.4 \mathrm{~g} / \mathrm{m}^{2}$, respectively. A detailed parameterization of leaf canopy development in APSIM was not performed because these parameters are (1) considered as species-specific, and (2) require measurement data on vertical profiles of leaf size and number in crop canopy (van Oosterom et al. 2010), which were not available when sampling plants at unit area basis.

Both iCrop and APSIM use the specific leaf nitrogen (SLN) approach for simulating the response of leaf canopy development to $\mathrm{N}$ availability. Experimental data on SLN showed a declining pattern from 34 days after sowing (DAS) in all $\mathrm{N}$ treatments. Nitrogen fertilization had a significant effect on SLN. The average SLN from 34 to 63 (silking) DAS was $1.75,1.90$, and $2.15 \mathrm{~g} / \mathrm{m}^{2}$ in N0, N1, and N4 treatment, respectively (Fig. 9). The default value for target or critical SLN in both models was set to $1.9 \mathrm{~g} \mathrm{~N} / \mathrm{m}^{2}$ from the $\mathrm{N} 1$ treatment because higher values of SLN and total plant $\mathrm{N}$ uptake in N3 and N4 treatments did not result in significant improvement in crop growth and grain yield. The SLN of senesced leaves in both models was set to the observed value of $0.3 \mathrm{~g} / \mathrm{m}^{2}$ measured in N0 plots. Similar to SLN, stem N\% declined during the crop growth period with N0 plants showing consistently lower stem N\% until silking (63 DAS) (Fig. 9). The average maximum stem N\% was $0.0425 \mathrm{~g} / \mathrm{g}$ at 21 DAS and decreased to $0.0042 \mathrm{~g} / \mathrm{g}$ at crop harvest. The target or green stem $\mathrm{N} \%$ in both models was set to $0.0333 \mathrm{~g} / \mathrm{g}$ measured at 34 DAS in N1 plants. Stem N\% at harvest (124 DAS) was on average $0.0042 \mathrm{~g} / \mathrm{g}$ and was not affected by $\mathrm{N}$ fertilization. The minimum stem N\% in N0 plants $(0.0032 \mathrm{~g} / \mathrm{g})$ was similar to default values for structural stem N\% in APSIM. For N\% in senesced stem, the iCrop code was modified to allow setting two values: a higher value from emergence to begin grain growth (SNCS1) and a lower value for the grain-filling period (SNCS2) (Table 5). This resulted in reduction in leaf area due to $\mathrm{N}$ stress during the vegetative growth as measured in the experiments.

Grain N\% in maize ranges from 0.0076 to $0.0166 \mathrm{~g} / \mathrm{g}$ (Tenorio et al. 2019). In the current study, grain $\mathrm{N} \%$ was 0.0114 and $0.0176 \mathrm{~g} / \mathrm{g}$ in N0 and N4 treatments of 2017, respectively. As iCrop uses only one value for minimum (GNCmin) and maximum (GNCmax) grain N\% during the grain-filling period, GNCmin and GNCmax had to be set to 0.0090 and $0.0300 \mathrm{~g} / \mathrm{g}$, respectively, to match the simulated grain N\% with observed data (see Table 5). Although the 
Fig. 5 Maize total above-ground biomass, leaf area index (LAI), and nitrogen $(\mathrm{N})$ uptake measured (symbols) and simulated (curves) by iCrop and APSIM with partial parameterization under 0 (N0) and 160 (N4) kg/ ha of nitrogen fertilization in 2017; bars indicate standard error of measured values

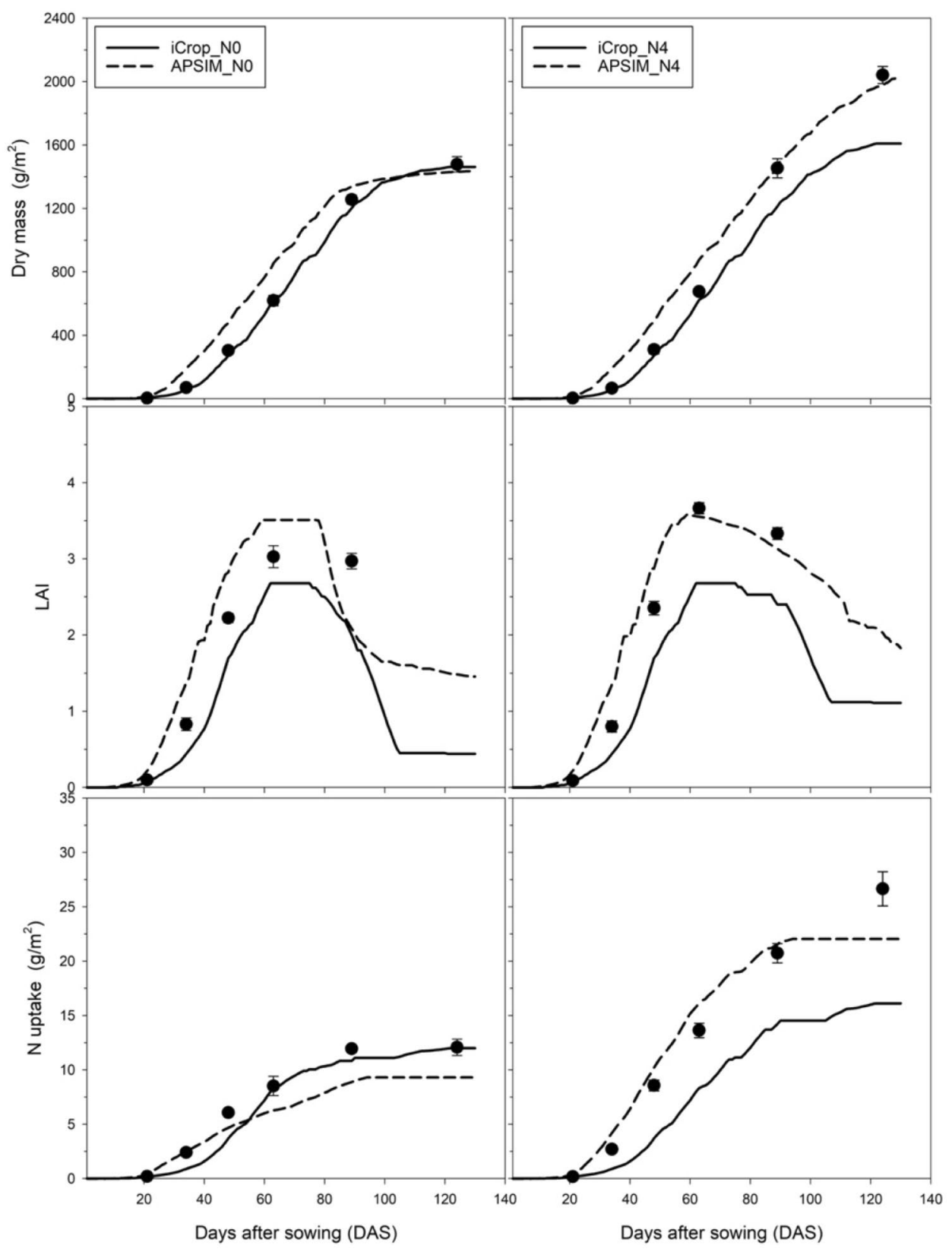

chosen values were different with means observed in $\mathrm{N} 0$ and N4 treatments, they were not in dis-agreement with observations in experimental plots.

In both crop models, there is a parameter for limiting the daily rate of plant $\mathrm{N}$ uptake. In iCrop, the maximum uptake rate of nitrogen (MXNUP) is expressed as $\mathrm{g} / \mathrm{m}^{2} /$ day, whereas in APSIM the corresponding parameter (maxUptakeRate) is a function of degree-days. The calculated values for this parameter using the plant $\mathrm{N}$ uptake data between 34 and 63 DAS in N4 treatment was lower than the default value in iCrop and higher than the default value in APSIM (see Table 5).
The simulated $\mathrm{N}$ uptake dynamics for ParLevel_1 showed that APSIM ceases $\mathrm{N}$ uptake quite early in the reproductive phase resulting in underestimation of final $\mathrm{N}$ uptake in all $\mathrm{N}$ treatments (see Fig. 5). Therefore, the timing of $\mathrm{N}$ uptake cessation in APSIM (nUptakeCease) was changed from the default value of $523-700{ }^{\circ} \mathrm{Cd}$, which resulted in $\mathrm{N}$ uptake up until 5 weeks after silking in the maize experiments of current research. This is supported by Soufizadeh et al. (2018) who reported that maize plants continue with $\mathrm{N}$ uptake up until 4-6 weeks after silking.

Grain yield in APSIM is simulated as the product of grain number and grain size (Soufizadeh et al. 2018). In ParLevel_1 simulations, APSIM predicted on average 
Fig. 6 Relationship between measured and simulated nitrogen $(\mathrm{N})$ uptake and grain yield of maize grown in 2016 and 2017 seasons under various levels of $\mathrm{N}$ fertilization for iCrop (a) and APSIM (b) models with partial parameterization
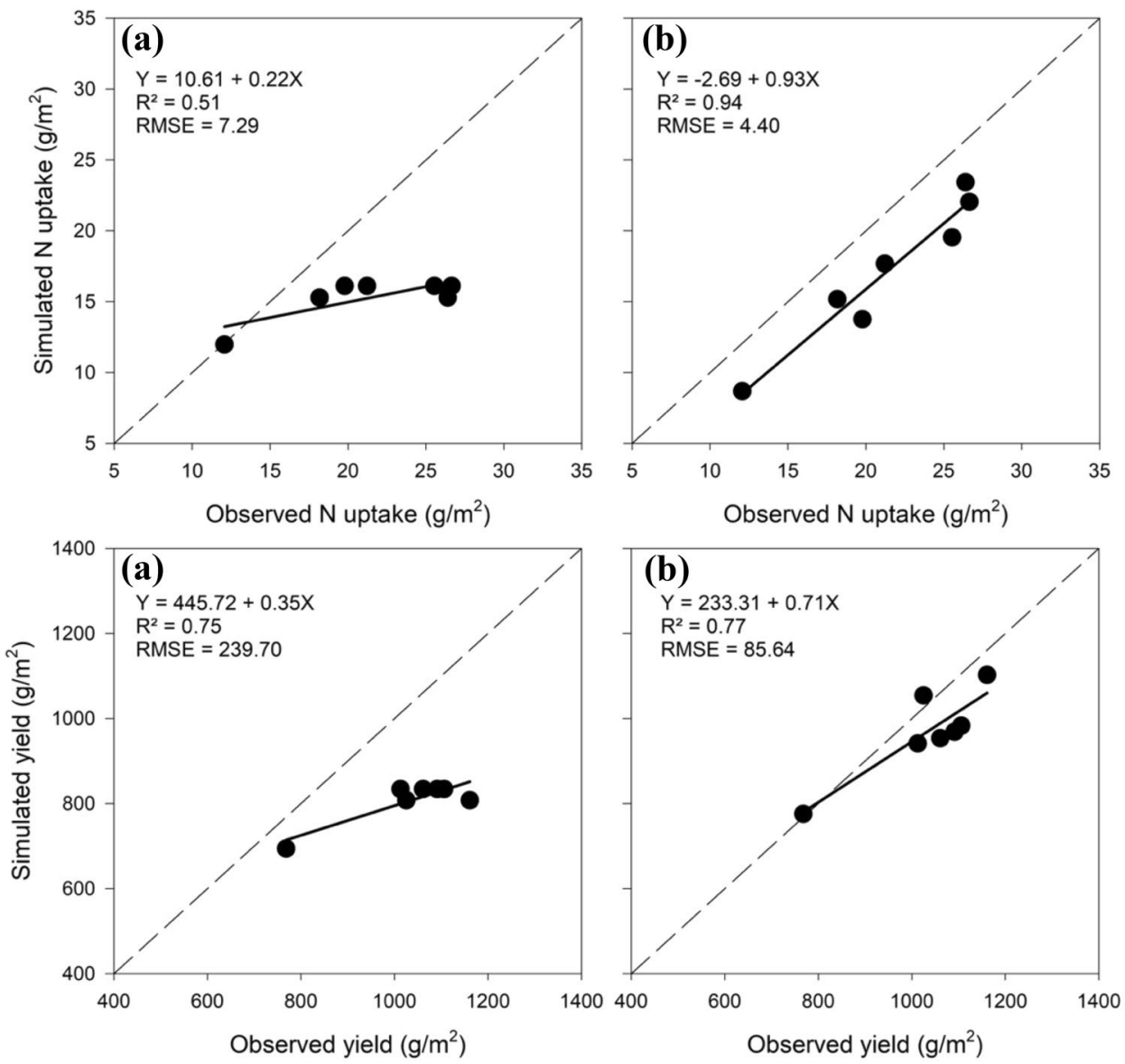

3356.3 grains per $\mathrm{m}^{2}$ across all $\mathrm{N}$ treatments, whereas the average observed grain number was 3899.9. To account for this underestimation, the default value of the parameter GNk was increased to 1.7. With this modification, the simulated grain number of fertilised plants (3992.2) matched well the observed data (3899.9). Similarly, the potential slope of harvest index (PDHI) in iCrop was increased to improve the grain yield of fertilised crops (see Table 5).

Following the modifications made in both models (see Table 5), the ParLevel_2 parameterization improved the iCrop and APSIM simulations of dry mass production, LAI, and $\mathrm{N}$ uptake in all $\mathrm{N}$ treatments (Fig. 10). Similarly, compared to ParLevel_1, simulations of total $\mathrm{N}$ uptake and grain yield by both models were improved substantially (Fig. 11). Improvements in the simulation of plant $\mathrm{N}$ uptake resulted in accurate predictions of dynamics of soil mineral $\mathrm{N}(\mathrm{Nmin})$ content in both unfertilised and fertilised plots (Fig. 12).

\section{Discussion}

The field experiments were relatively successful in providing a range of data on total dry mass, grain yield, yield components, $\mathrm{N}$ uptake and LAI (Table 1). For these variables, maximum observed means were 40-120\% higher than minimum observed means. The weak response of maize yield and dry mass to $\mathrm{N}$ treatment, especially in the first experiment (2016), can be attributed to very high initial soil Nmin values (see Table 3 ). In addition, soils at the experimental site are very rich in organic carbon and $\mathrm{N}$ and, therefore, can supply substantial amounts of $\mathrm{N}$ through mineralisation of organic matter. For instance, maize plants in unfertilised plots in 2017 had accumulated $120.7 \mathrm{~kg} / \mathrm{ha}$ nitrogen with an initial soil Nmin of $66.0 \mathrm{~kg} / \mathrm{ha}$. Given that $27.9 \mathrm{~kg} / \mathrm{ha}$ of $\mathrm{N}$ was still available in the soil at crop harvest, the $\mathrm{N}$ balance (input-output) was $-82.6 \mathrm{~kg} / \mathrm{ha}$. Assuming soil as the only source of $\mathrm{N}$, this negative balance must have been compensated by mineralisation of soil organic matter. Therefore, for field research on crop responses to $\mathrm{N}$ supply on these soils, the previous crops should not be fertilised with $\mathrm{N}$ for at least 1-2 seasons.

With partial parameterization (ParLevel_1) based on observed phenological stages and main-stem leaf number, both models failed to provide accurate estimation of LAI, dry mass accumulation, $\mathrm{N}$ uptake and grain yield, but the performance of APSIM was generally better than iCrop (Figs. 5, 6). Thus, one possible important conclusion is 
Table 5 Cultivar-specific input parameters for maize cv. P8500 used for the parameterisation of iCrop and APSIM for full parameterisation (ParLevel_2)

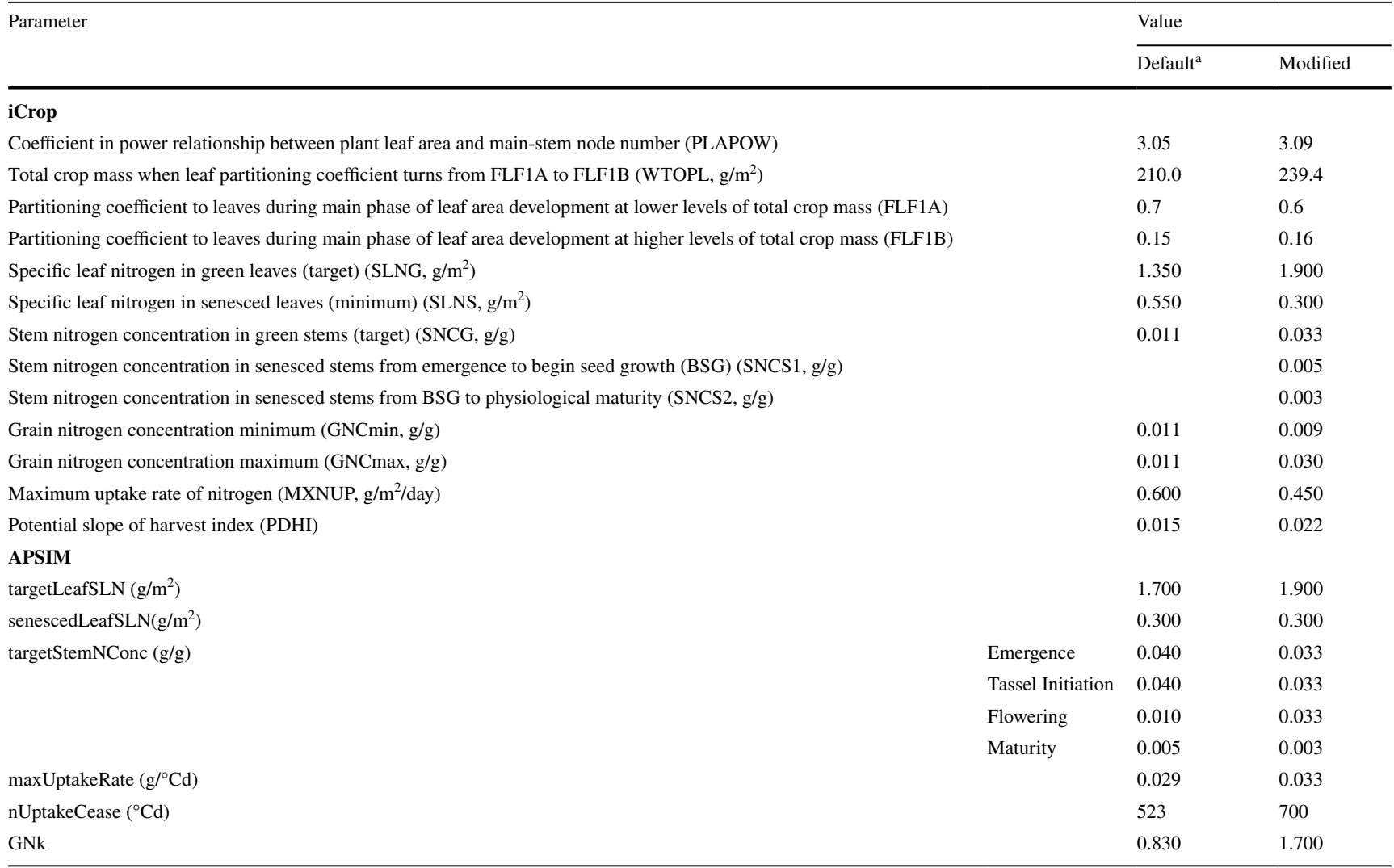

${ }^{a}$ For iCrop the default values were those reported in Soltani and Sinclair (2012)

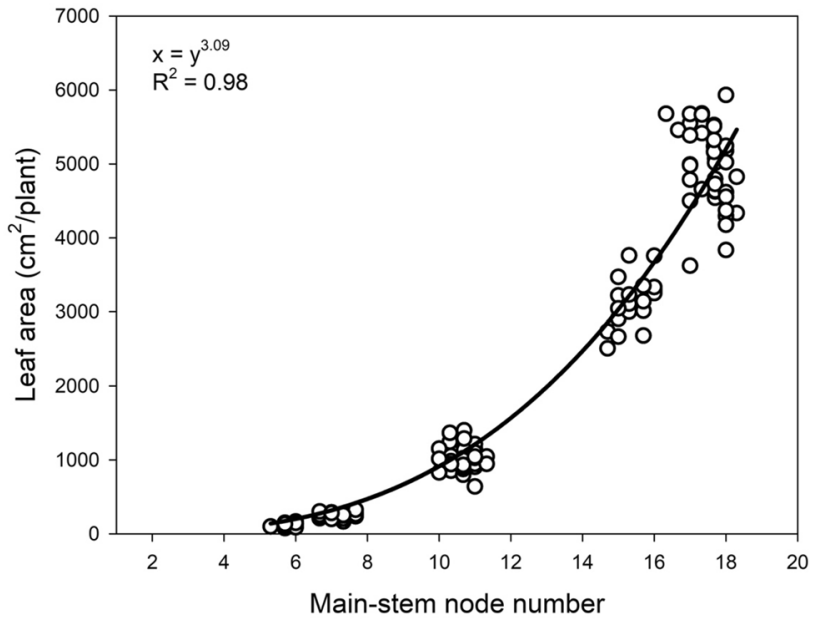

Fig. 7 Relationship between plant leaf area and main-stem node number of maize cultivar P8500 grown in 2016 and 2017 growing seasons

that the simple model iCrop was more sensitive to parameterization. Detailed models like APSIM use many more equations and parameters (species and cultivar-specific parameters) to describe crop processes and their responses

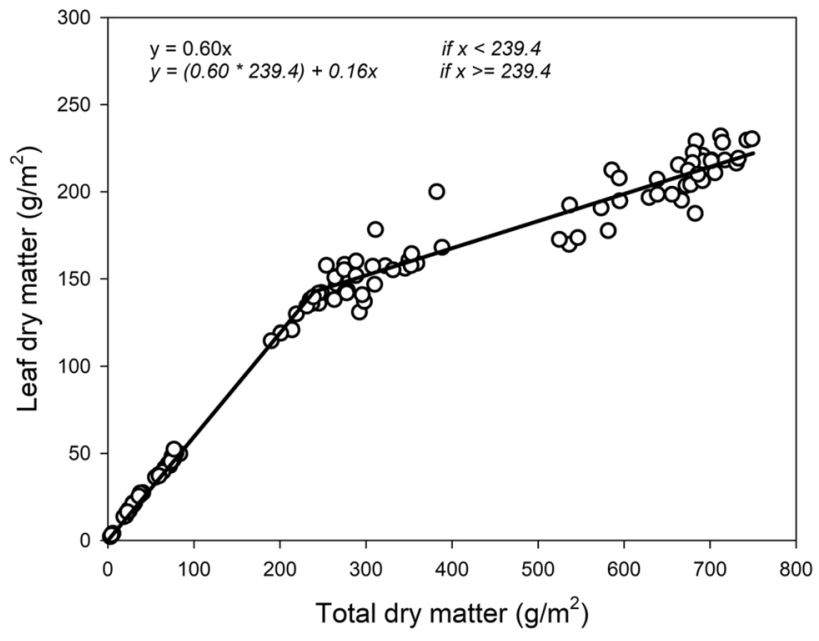

Fig. 8 Relationship between leaf dry matter and total plant dry matter of maize cultivar P8500 grown in 2016 and 2017 growing seasons

to the environment; this probably prevents the model from out of range predictions under new conditions. Thus, simple models need better attention to parameterization under new conditions, but this needs to be confirmed by future studies. 

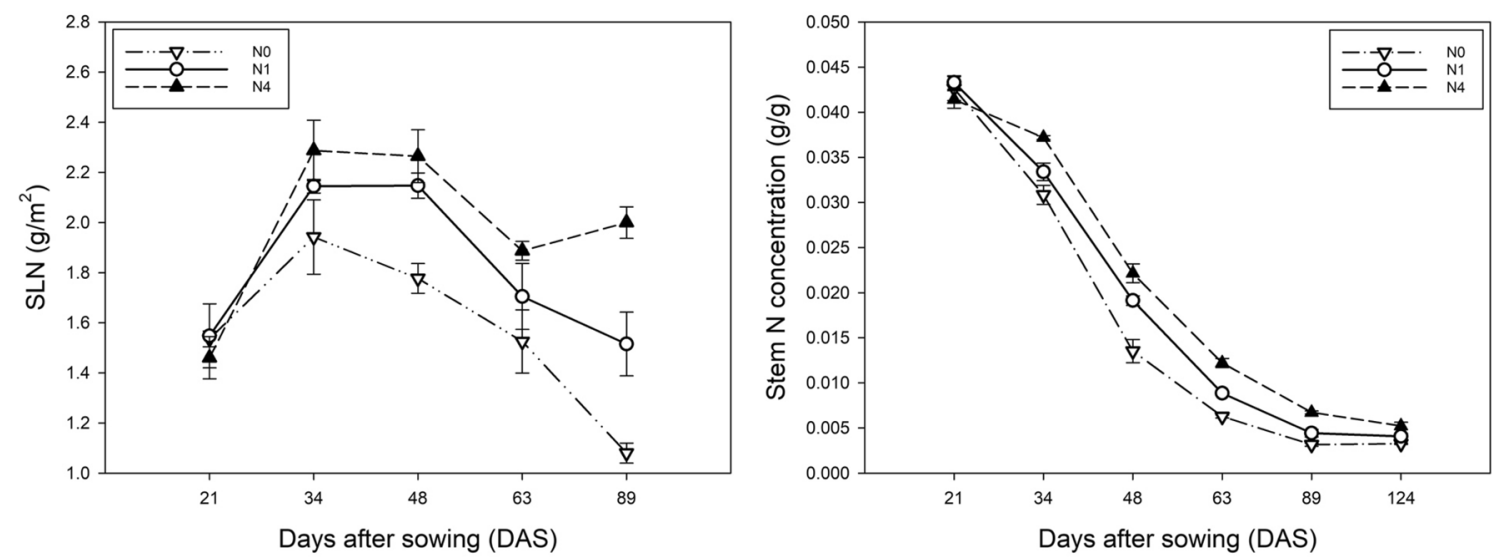

Fig. 9 Specific green leaf nitrogen content (SLN) and stem nitrogen (N) concentration of maize plants grown in 2017 under 0 (N0), 40 (N1) and $160(\mathrm{~N} 4) \mathrm{kg} / \mathrm{ha}$ of nitrogen

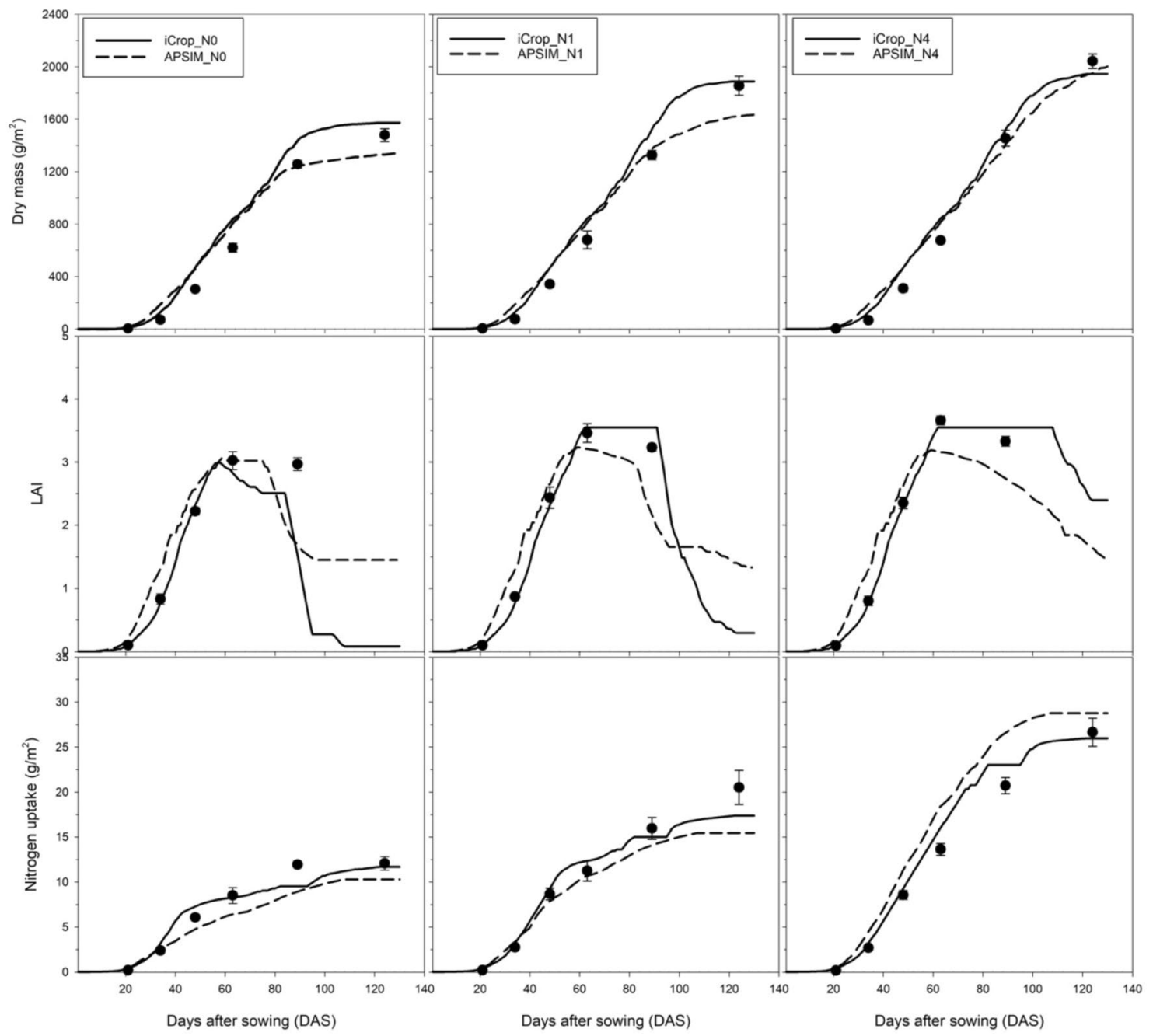

Fig. 10 Maize total above-ground biomass, leaf area index (LAI), and nitrogen $(\mathrm{N})$ uptake measured (symbols) and simulated (curves) by iCrop and APSIM with full parameterization under 0 (NO), 40 (N1) and 160 (N4) kg/ha of nitrogen in 2017; bars indicate standard error of measured values 
Fig. 11 Relationship between measured and simulated nitrogen $(\mathrm{N})$ uptake and grain yield of maize grown in 2016 and 2017 seasons under various levels of $\mathrm{N}$ fertilization for iCrop (a) and APSIM (b) models with full parameterization
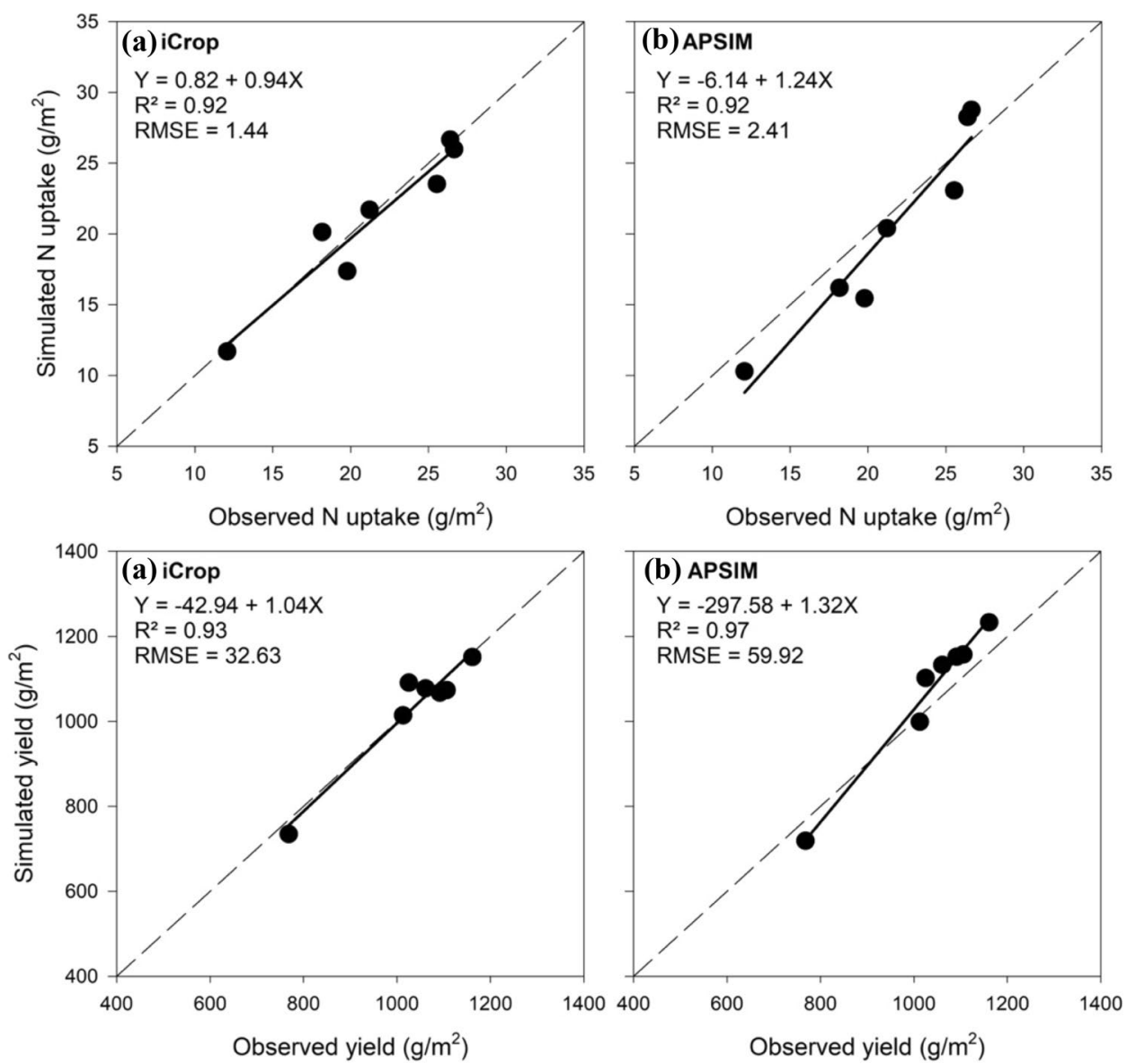
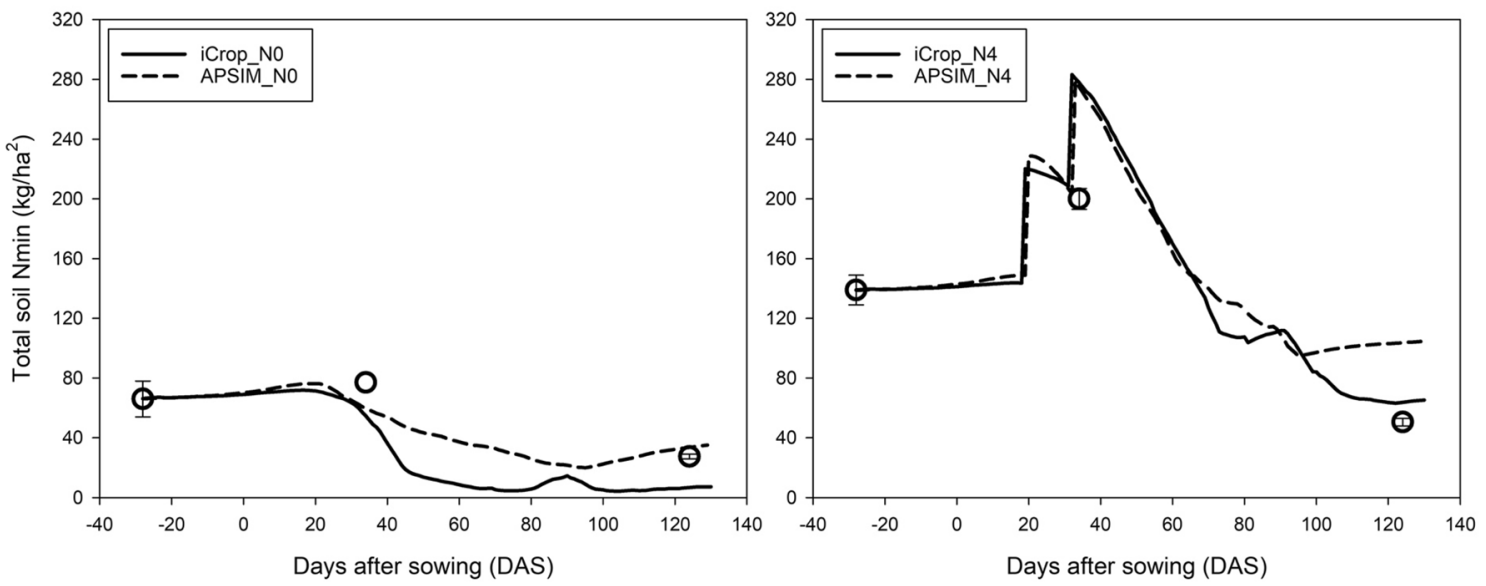

Fig. 12 Soil mineral nitrogen (Nmin) measured and simulated by iCrop and APSIM models in unfertilised (N0) and highly fertilised (N4; $160 \mathrm{~kg} / \mathrm{ha}$ ) maize plants grown in 2017; bars indicate standard error of measured values

The results of the current study certainly support the conclusion that partial parameterization may not be enough and does not guarantee improved performance of both simple and complex models under new situations. Palosuo et al. (2011) applied a "blind test" in comparison of eight wheat models and concluded that none of the models perfectly reproduced recorded observations, and none were unequivocally accurate. In this "blind test" only phenological data were provided to the modeller to test the capability of their models to reproduce yields and yield variability under different climatic conditions in Europe. He et al. (2017) in evaluation of a range of experimental data in the parameterization 
of APSIM-Canola showed that model parameterization needs to be carefully performed before the model can be used to simulate crop growth across diverse environments and management scenarios.

Full parameterization (ParLevel_2) greatly improved the performance of both crop models in simulation of dynamics of dry mass accumulation, LAI and $\mathrm{N}$ uptake over the growing seasons (Fig. 10) and in predicting final $\mathrm{N}$ uptake and grain yield (Fig. 11). The performance of the simple model (iCrop) was as good as or better than the complex model (APSIM). This is in agreement with previously reported findings by Soltani and Sinclair (2015) in comparison of four wheat models. They indicated that the coefficient of variation in prediction of grain yield was about $45 \%$ lower for iCrop compared to APSIM. They concluded that sacrification of transparency by adding more functions/parameters was not rewarded by increased model robustness. There are some other studies that have indicated increased complexity of a model does not increase the robustness of the model (e.g. Bell and Fischer 1994; Goudriaan 1996; Adam et al. 2011). For example, Adam et al. (2011) compared a simple and a detailed approach for simulating dry matter production and LAI dynamics and did not find any advantage of one approach to the other one. Zhao et al. (2019) indicated that the performance of a new simple crop model (SIMPLE) was comparable to the models with more details (DSSAT and APSIM). Sinclair and Seligman (2000) had stated that models should be kept as simple as possible.

The results of the current study confirm that there is a need to generate and compile high-quality data sets for parameterization and testing of crop models (Rosenzweig et al. 2014; Grassini et al. 2015). Such data sets should include not only production-related parameters such as crop yield but also cover temporal patterns of crop growth variables as well as dynamics of soil water, carbon, and $\mathrm{N}$. The importance of good quality comprehensive data sets for better parameterization and testing of crop models has also been frequently highlighted by European and international climate change impact assessment research efforts such as AgMIP (https://www.agmip.org).

The results of the current study also support the conclusion that the role of model parameterization cannot be ignored (He et al. 2017) and it is something in which more investment is needed (Confalonieri et al. 2016). Seidel et al. (2018) did a large-scale survey of crop model calibration practices (211 responses) conducted among the various crop modelling teams and showed that there is a very large variability in approaches to crop model calibration. They concluded that a wide range of approaches and choices are utilized for model calibration and it would be very useful to provide guidelines for crop model calibration.

The iCrop model needed modification during ParLevel_2. It was required to define two values for senesced stem N\% instead of one in the original model (SNCS) in order to improve the simulation of LAI response to $\mathrm{N}$ stress. When using only one value for senesced stem $\mathrm{N} \%, \mathrm{~N}$ stress during the vegetative growth in iCrop causes translocation of stem $\mathrm{N}$ to meet the leaf $\mathrm{N}$ demand. Therefore, the relatively low default value of SNCS prevented the reduction in LAI under N stress (see Fig. 5). Introducing two SNCS values (see Table 5) resulted in a reduction of LAI under $\mathrm{N}$ stress without affecting the translocation of $\mathrm{N}$ from stem during the grain filling phase. Modifications in iCrop are simple and straightforward as the model is written in Visual Basic for Application (VBA) in Excel and codes are open-access and handy for such manipulations.

One of the principles of iCrop is to evaluate the model assumption in view of the objectives of the current model situation and add new hypotheses and modify the model if it is required (Sinclair and Seligman 1996; Soltani and Sinclair 2012). For such modifications the crop model needs to be transparent. For transparency, model parameters and code should be accessible and readily understood by model users (van Ittersum et al. 2003; Soltani and Sinclair 2012). Transparency is facilitated by a minimum number of parameters that can be independently observed and measured. Often, transparency is diminished as the complexity of a model is increased (Soltani and Sinclair 2015).

One important finding from the current study is that simple crop models may better respond to parameterization than the complex models. ParLevel_2 was more effective for the simple model iCrop. While the performance of iCrop was equally well compared to APSIM in prediction of dynamics of dry mass accumulation, LAI and $\mathrm{N}$ uptake during the growing season (Fig. 10), it outperformed APSIM in prediction of final $\mathrm{N}$ uptake and grain yield; RMSEs (root mean square errors) were $\geq 40 \%$ lower for iCrop compared to APSIM (Fig. 11). A potential reason for that behaviour might be that there were remaining parameters for APSIM, which are not classified as cultivar-parameters and, therefore, were not parameterised. Even if they were classified as cultivar-specific parameters, it might not help because experimental data to calculate the parameters (e.g. leaf canopy development) are often not available.

Studies that have evaluated the impact of parameterization level on model predictions are limited. While modelling studies indicate higher levels of parameterization generally improves model performance, they have not attempted to separate the results in terms of complexity of the crop models applied, i.e. simple versus complex models. Bassu et al. (2014) inter-compared 23 maize models under two levels of input information and showed that variability of model predictions was strongly reduced when the level of input information in model parameterization increased. Similarly, Battisti et al. (2017) compared five soybean models under three phases of parameterization: no parameterization using 
default parameters, partial parameterization using phenology data, and complete parameterization using phenology and growth data. They found that model performance improved from no parameterization phase to complete parameterization. Asseng et al. (2013) evaluated uncertainty of 27 wheat models, partially or fully parameterized, in simulation of wheat. Full parameterization reduced relative RMSE in prediction of all simulated variables associated with phenology, dry mass production, evapotranspiration, crop $\mathrm{N}$ uptake and yield.

\section{Conclusion}

Partial parameterization (ParLevel_1) was not adequate for best performance of the simple (iCrop) and detailed (APSIM) crop models used in the current study, although APSIM performed better at this parameterization level. iCrop was, therefore, more vulnerable to incomplete parameterization than APSIM. However, iCrop better responded to complete parameterisation and its performance was even better than the detailed model. This is because the parameters governing leaf canopy development and biomass partitioning in iCrop can easily be derived from experimental data. More research with other simple and detailed models is required to confirm the results of the current research. Complete parameterisation should not be passed over easily if model predictions matter.

Acknowledgements We wish also to thank Prof. Hermann Bürstmayr (IFA-Tulln) for providing the infrastructure for experiments and Mr. Matthias Fidesser for his excellent assistance in conducting the field experiments.

Funding Open access funding provided by University of Natural Resources and Life Sciences Vienna (BOKU). This study was conducted within the framework of the research projects COMBIRISK and FarmIT. Financial support from the Austrian Climate Research Program (ACRP) and the Austrian Research Promotion Agency (FFG) is gratefully acknowledged.

\section{Compliance with Ethical Standards}

Conflict of interest The authors declare there are no conflicts of interest.

Open Access This article is licensed under a Creative Commons Attribution 4.0 International License, which permits use, sharing, adaptation, distribution and reproduction in any medium or format, as long as you give appropriate credit to the original author(s) and the source, provide a link to the Creative Commons licence, and indicate if changes were made. The images or other third party material in this article are included in the article's Creative Commons licence, unless indicated otherwise in a credit line to the material. If material is not included in the article's Creative Commons licence and your intended use is not permitted by statutory regulation or exceeds the permitted use, you will need to obtain permission directly from the copyright holder. To view a copy of this licence, visit http://creativecommons.org/licenses/by/4.0/.

\section{References}

Adam, M., van Bussel, L. G. J., Leffelaar, P. A., van Keulen, H., \& Ewert, F. (2011). Effects of modelling detail on simulated potential crop yields under a wide range of climatic conditions. Ecological Modelling, 222, 131-143.

Asseng, S., Ewert, F., Rosenzweig, C., Jones, J. W., Hatfield, J. L., Ruane, A. C., et al. (2013). Uncertainty in simulating wheat yields under climate change. Nature Climate Change, 3(9), $827-832$.

Bassu, S., Brisson, N., Durand, J.-L., Boote, K., Lizaso, J., Jones, J. W., et al. (2014). How do various maize crop models vary in their responses to climate change factors? Global Change Biology, 20(7), 2301-2320.

Battisti, R., Sentelhas, P. C., \& Boote, K. J. (2017). Inter-comparison of performance of soybean crop simulation models and their ensemble in southern Brazil. Field Crop Research, 200, 28-37.

Bell, M. A., \& Fischer, R. A. (1994). Using yield prediction models to assess yield gains: A case study for wheat. Field Crop Research, 36, 161-166.

BMLFUW. (2017). Richtlinie für die sachgerechte Düngung im Ackerbau und Grünland Bundesministerium für Land- und Forstwirtschaft. Vienna: Umwelt und Wasserwirtschaft.

Chenu, K., van Oosterom, E. J., McLean, G., Deifel, K. S., Fletcher, A., Geetika, G., et al. (2018). Integrating modelling and phenotyping approaches to identify and screen complex traits: Transpiration efficiency in cereals. Journal of Experimental Botany, 69(13), 3181-3194.

Confalonieri, R., Bregaglio, S., \& Acutis, M. (2016). Quantifying uncertainty in crop model predictions due to the uncertainty in the observations used for calibration. Ecological Modelling, $328,72-77$.

Dalgliesh, N. P., \& Foale, M. A. (1998). Soil matters: Monitoring soil water and nitrogen in dryland farming agricultural production systems research unit (p. 122). Toowoomba: CSIRO.

Dalla Marta, A., Eitzinger, J., Kersebaum, K. C., Todorovic, M., \& Altobelli, F. (2018). Assessment and monitoring of crop water use and productivity in response to climate change. Journal of Agricultural Science, 156(5), 575-576.

Devkota, K. P., Manschadi, A. M., Devkota, M., Lamers, J. P. A., Ruzibaev, E., Egamberdiev, O., et al. (2013). Simulating the impact of climate change on rice phenology and grain yield in irrigated drylands of Central Asia. Journal of Applied Meteorology and Climatology, 52, 2033-2050.

Ebrahimi, E., Manschadi, A. M., Neugschwandtner, R. W., Eitzinger, J., Thaler, S., \& Kaul, H.-P. (2016). Assessing the impact of climate change on crop management in winter wheat: A case study for Eastern Austria. Journal of Agricultural Science, 154(7), 1153-1170.

Eitzinger, J., Thaler, S., Schmid, E., Strauss, F., Ferrise, R., Moriondo, M., et al. (2013b). Sensitivities of crop models to extreme weather conditions during flowering period demonstrated for maize and winter wheat in Austria. Journal of Agricultural Science, 151, 813-835.

Eitzinger, J., Trnka, M., Semerádo, D., Thaler, S., Svobodová, E., Hlavinka, P., et al. (2013a). Regional climate change impacts on 33 agricultural crop production in Central and Eastern Europe: Hotspots, regional differences and 34 common trends. Journal of Agricultural Science, 151(6), 787-812.

Ewert, F., Rötter, R. P., Bindi, M., Webber, H., Trnka, M., Kersebaum, K. C., et al. (2015). Crop modelling for integrated 
assessment of risk to food production from climate change. Environmental Modelling \& Software, 72, 287-303.

Ghanem, M. E., Marrou, H., Biradar, C., \& Sinclair, T. R. (2015). Production potential of lentil (Lens culinaris Medik.) in East Africa. Agricultural Systems, 137, 24-38.

Gobin, A., Kersebaum, K. C., Eitzinger, J., Trnka, M., Hlavinka, P., Takac, J., et al. (2017). Variability in the water footprint of arable crop production across European Regions. Water, 9(2), $1-22$.

Goudriaan, J. (1996). Predicting crop yields under global change. In B. H. Walker \& W. Steffen (Eds.), Global change and terrestrial ecosystems. Cambridge: Cambridge University Press.

Grassini, P., van Bussel, L. G. J., van Warta, J., Wolf, J., Claessens, L., Yanga, H., et al. (2015). How good is good enough? Data requirements for reliable crop yield simulations and yield-gap analysis. Field Crops Research, 177, 49-63.

Hammer, G., Messina, C., Wu, A., \& Cooper, M. (2019). Biological reality and parsimony in crop models - why we need both in crop improvement! In Silico Plants. https://doi.org/10.1093/insilicopl ants/diz010.

Hammer, G. L., van Oosterom, E., McLean, G., Chapman, S. C., Broad, I., Harland, P., et al. (2010). Adapting APSIM to model the physiology and genetics of complex adaptive traits in field crops. Journal of Experimental Botany, 61(8), 2185-2202.

He, D., Wang, E., Wang, J., \& Robertson, M. J. (2017). Data requirement for effective calibration of process-based crop models. Agricultural and Forest Meteorology, 234-235, 136-148.

Hochman, Z., Rees, H., Carberry, P. S., Hunt, J. R., McCown, R. L., Gartmann, A., et al. (2009). Re-inventing model-based decision support with Australian dryland farmers. 4. Yield Prophet ${ }^{\circledR}$ helps farmers monitor and manage crops in a variable climate. Crop \& Pasture Science, 60, 1057-1070.

Holzworth, D. P., Huth, N. I., deVoil, P. G., Zurcher, E. J., Herrmann, N. I., McLean, G., et al. (2014). APSIM: Evolution towards a new generation of agricultural systems simulation. Environmental Modelling \& Software, 62, 327-350.

Huth, N. I., Thorburn, P. J., Radford, B. J., \& Thornton, C. M. (2010). Impacts of fertilisers and legumes on $\mathrm{N}_{2} \mathrm{O}$ and $\mathrm{CO}_{2}$ emissions from soils in subtropical agricultural systems: A simulation study. Agriculture, Ecosystems \& Environment, 136(3-4), 351-357.

Kiniry, J. R. (1991). Maize phasic development. In J. Hanks \& J. T. Ritchie (Eds.), Modeling plant and soil systems (Chapter 4) (pp. 55-70). Madison: American Society of Agronomy.

Knutti, R., \& Sedlácek, J. (2013). Robustness and uncertainties in the new CMIP5 climate model projections. Nature Climate Change, 3, 369-373.

Lobell, D. B., Hammer, G. L., Chenu, K., Zheng, B., McLean, G., \& Chapman, S. C. (2015). The shifting influence of drought and heat stress for crops in Northeast Australia. Global Change Biology, 21, 4115-4127.

Manschadi, A. M., Christopher, J., deVoil, P., \& Hammer, G. L. (2006). The role of root architectural traits in adaptation of wheat to waterlimited environments. Functional Plant Biology, 33, 823-837.

Manschadi, A. M., Kaul, H.-K., Vollmann, J., Eitzinger, J., \& Wenzel, W. (2014). Developing phosphorus-efficient crop varieties-An interdisciplinary research framework. Field Crops Research, 162, 87-98.

Meier, U. (2001). Growth stages of mono- and dicotyledonous plants: BBCH Monograph (2nd ed.). Bonn: Federal Biological Research Centre for Agriculture and Forestry.

Messina, C. D., Sinclair, T. R., Hammer, G. L., Curan, D., Thompson, J., Oler, Z., et al. (2015). Limited-transpiration trait may increase maize drought tolerance in the US Corn Belt. Agronomy Journal, 107(6), 1978-1986.

Moeller, C., Pala, M., Manschadi, A. M., Meinke, H., \& Sauerborn, J. (2007). Assessing the sustainability of wheat-based cropping systems using APSIM: Model parameterisation and evaluation. Australian Journal of Agricultural Research, 58, 75-86.

Moeller, C., Sauerborn, J., de Voil, P., Manschadi, A. M., Pala, M., \& Meinke, H. (2013). Assessing the sustainability of wheat-based cropping systems using simulation modelling: Sustainability $=$ 42? Sustainability Science, 9(1), 1-16.

Palosuo, T., Kersebaum, K. C., Angulo, C., Hlavinka, P., Mirschel, W., Moriondo, M., et al. (2011). Simulation of winter wheat yields and yield variability in different climates of Europe: A comparison of eight crop growth models. European Journal of Agronomy, 35, 103-114.

Rosenzweig, C., Elliott, J., Deryng, D., Ruane, A. C., Muller, C., Arneth, A., et al. (2014). Assessing agricultural risks of climate change in the 21 st century in a global gridded crop model intercomparison. Proceedings of the National Academy of Sciences of the United States of America, 111, 3268-3273.

Rötter, R. P., Carter, T. R., Olesen, J. E., \& Porter, J. R. (2011). Crop-climate models need an overhaul. Nature Climate Change, $1,175-177$.

Rötter, R. P., Palosuo, T., Kersebaum, K. C., Angulo, C., Bindi, M., Ewert, F., et al. (2012). Simulation of spring barley yield in different climatic zones of Northern and Central Europe: A comparison of nine crop models. Field Crops Research, 133, 23-36.

Salo, T., Palosuo, T., Kersebaum, K., Nendel, C., Angulo, C., Ewert, F., et al. (2016). Comparing the performance of 11 crop simulation models in predicting yield response to nitrogen fertilization. The Journal of Agricultural Science, 154(7), 1218-1240.

SAS-Institute. (2008). SAS 92 Copyright 2002-2008. Cary: SAS Institute Inc.

Seidel, S. J., Palosuo, T., Thorburn, P., \& Wallach, D. (2018). Towards improved calibration of crop models: Where are we now and where should we go? European Journal of Agronomy, 94, 25-35.

Sinclair, T. R. (1986). Water and nitrogen limitations in soybean grain production I. Model development. Field Crops Research, 15(2), $125-141$.

Sinclair, T. R., \& Muchow, R. C. (1995). Effect of nitrogen supply on maize yield: I. Modeling physiological responses. Agronomy Journal, 87(4), 632-641.

Sinclair, T. L., \& Seligman, G. (1996). Crop modeling: From infancy to maturity. Agronomy Journal, 88(5), 698-704.

Sinclair, T. R., \& Seligman, N. (2000). Criteria for publishing papers on crop modeling. Field Crops Research, 68, 165-172.

Sinclair, T. R., Soltani, A., Marrou, H., Ghanem, M., \& Vadez, V. (2020). Geospatial assessment for crop genetic and management improvements. Crop Science. https://doi.org/10.1002/csc2.20106.

Soltani, A., Maddah, V., \& Sinclair, T. R. (2013). SSM-Wheat: A simulation model for wheat development, growth and yield. International Journal of Plant Production, 7(4), 711-740.

Soltani, A., \& Sinclair, T. R. (2012). Modeling physiology of crop development, growth and yield. Wallingford: CABI.

Soltani, A., \& Sinclair, T. R. (2015). A comparison of four wheat models with respect to robustness and transparency: Simulation in a temperate, sub-humid environment. Field Crops Research, 175, $37-46$.

Soufizadeh, S., Munaro, E., McLean, G., Massigna, E., van Oosterom, E. J., Chapman, S. C., et al. (2018). Modelling the nitrogen dynamics of maize crops: Enhancing the APSIM maize model. European Journal of Agronomy, 100, 118-131.

StClair, S. B., \& Lynch, J. P. (2010). The opening of Pandora's Box: Climate change impacts on soil fertility and crop nutrition in developing countries. Plant and Soil, 335, 101-115.

Tang, J., Wang, J., Fang, Q., Wang, E., Yin, H., \& Pan, X. (2018). Optimizing planting date and supplemental irrigation for potato across the agro-pastoral ecotone in North China. European Journal of Agronomy, 98, 82-94. 
Tenorio, F. A. M., Eagle, A. J., McLellan, E. L., Cassman, K. G., Howard, R., Below, F. E., et al. (2019). Assessing variation in maize grain nitrogen concentration and its implications for estimating nitrogen balance in the US North Central region. Field Crops Research, 240, 185-193.

Thaler, S., Eitzinger, J., Trnka, M., \& Dubrovsky, M. (2012). Impacts of climate change and alternative adaptation options on winter wheat yield and water productivity in a dry climate in Central Europe. Journal of Agricultural Science, 150(05), 537-555.

Van der Velde, M., \& Nisini, L. (2018). Performance of the MARScrop yield forecasting system for the European Union: Assessing accuracy, in-season, and year-to-year improvements from 1993 to 2015. Agricultural Systems, 168, 224-230.

Van Ittersum, M. K., Leffelaar, P. A., van Keulen, H., Kropff, M. J., Bastiaans, L., \& Goudriaan, J. (2003). On approaches and applications of the Wageningen crop model. European Journal of Agronomy, 18, 201-234.

van Oosterom, E. J., Borrell, A. K., Chapman, S. C., Broad, I. J., \& Hammer, G. L. (2010). Functional dynamics of the nitrogen balance of sorghum: I N demand of vegetative plant parts. Field Crops Research, 115, 19-28.

Wallach, D., Buis, S., Lecharpentier, P., Bourges, J., Clastre, P., Launay, M., et al. (2011). A package of parameter estimation methods and implementation for the STICS crop-soil model. Environmental Modelling \& Software, 26, 386-394.

White, J. W., Hoogenboom, G., Kimbal, B. A., \& Wall, G. W. (2011). Methodologies for simulating impacts of climate change on crop production. Field Crops Research, 124, 357-368.

Wu, A., Hammer, G. L., Doherty, A., von Caemmerer, S., \& Farquhar, G. D. (2019). Quantifying impacts of enhancing photosynthesis on crop yield. Nature Plants, 5, 380-388.

Zhao, C., Liu, B., Xiao, L., Hoogenboom, G., Boote, K. J., Kassie, B. T., et al. (2019). A SIMPLE crop model. European Journal of Agronomy, 104, 97-106. 